\title{
UNA REVISIÓN DEL MOSAICO DIONISÍACO DE LA VILLA ROMANA DE ALBALADEJO (CIUDAD REAL)
}

A REVISION OF THE DYONISIAN MOSAIC IN THE ROMAN VILLA OF ALBALADEJO (CIUDAD REAL)

CARMEN GARCÍA BUENO

Universidad de Castilla-La Mancha

carmengbueno2014@gmail.com http://orcid.org/0000-0001-6728-2426

Recepción: 30-05-2017

Aceptación: 28-07-2017

\section{Resumen}

A lo largo de las siguientes páginas intentamos profundizar en la lectura del único mosaico figurativo de esta villa que ha llegado hasta nuestros días. Además, queremos dar a conocer algunas noticias y material gráfico inéditos.

Palabras clave. Puente de la Olmilla; villa romana; Bajo Imperio; mosaico; thyasos.

\begin{abstract}
Over the next pages we will try to delve into the reading of the only figurative mosaic in this villa that has reached us. Furthermore, we want to share some inedit news and graphic material.
\end{abstract}

Key words. Puente de la Olmilla; Roman villa; Late Roman Empire; mosaic; thyasos. 
Dado que anteriormente hemos centrado nuestra atención en ciertos aspectos de este yacimiento arqueológico, para evitar ser reiterativos no insistiremos aquí en cuestiones tales como el medio físico, las condiciones determinantes de la ubicación de la villa (Fig. 1) o sus características arquitectónicas... (cfr., al respecto, García Bueno, 2011: 449-472; 2015a: 207-230; 2015b: 145-172; 2015c: 119-162).

El propósito de este trabajo es ofrecer un estudio detallado del mosaico que pavimentaba la habitación n. ${ }^{\circ} 2$ y también dar a conocer algunos datos y documentación gráfica de su proceso de descubrimiento, excavación ${ }^{1}$ y extracción, hasta ahora inéditos, que hemos recabado en el Archivo General de la Administración (Alcalá de Henares) y en el Museo Provincial de Ciudad Real (véase Anexo).

Este ejemplar es conocido como el «mosaico de las panteras», aunque en realidad los animales representados son leopardos, a juzgar por la piel con manchas moteadas de ambos felinos (Fig. 2), y ha sido previamente estudiado (Puig y Montanya, 1975: 138-139, 141-142, fig. 3; Blázquez, 1982c: 29-30, fig. 20, láms. 14-15 y 45, n. $\left.^{\circ} 24\right)$, sin embargo, vamos a detenernos de forma más exhaustiva en su análisis descriptivo y a ocuparnos de otras particularidades del mismo que no han sido tratadas con antelación, pero que consideramos importantes para su valoración específica en el contexto de los mosaicos de trasunto dionisíaco.

Cubría el suelo de un aposento de 2 × 4,70 m, un ámbito que precede y da paso a la dependencia $n .^{\circ} 1$, a modo de antesala (Fig. 3). Asociado a la decoración pictórica parietal (de la que aparecieron restos de
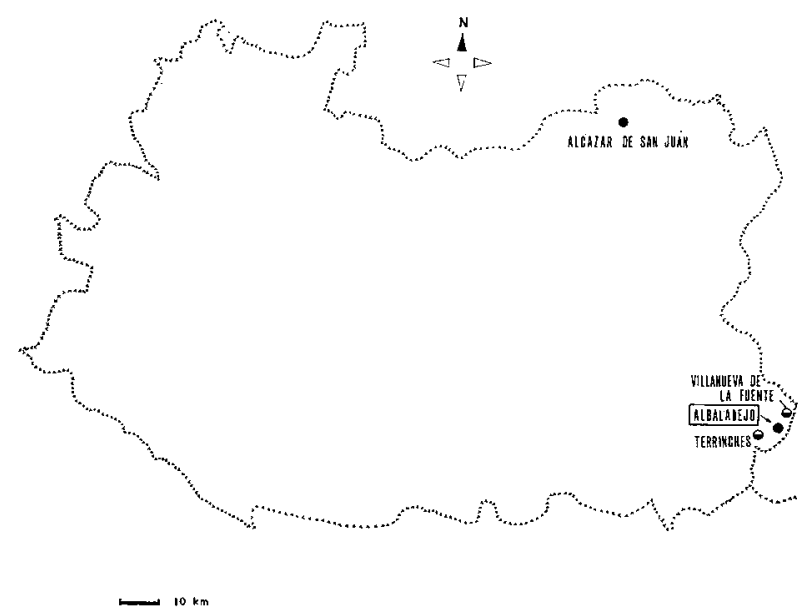

Figura 1: Mapa de situación de la villa (Gorges, 1979, lám. $\mathrm{XXI)}$.

1. Este mosaico fue excavado durante la campaña de 1974, que pertenece a la primera fase de intervención en este yacimiento, dirigida por M.R. Puig Ochoa y R. Montanya Maluquer. Después de la campaña de 1980 (la última en la que ambos participaron) se produjo un amplio intervalo de tiempo, reanudándose las labores arqueológicas años más tarde, bajo la dirección de quien suscribe (García Bueno, 2001: 212).

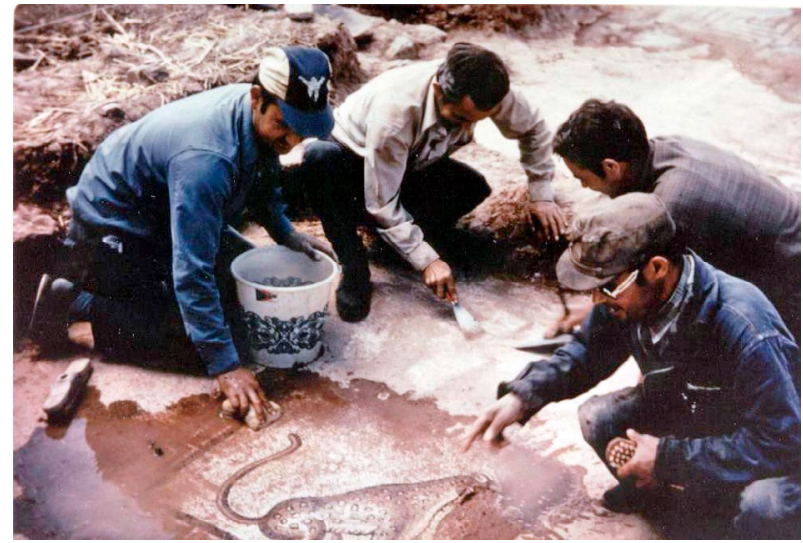

Figura 2: Detalle del mosaico, en proceso de excavación. Foto: Puig y Montanya (Museo Provincial de Ciudad Real).

estuco pintado de colores rojo, negro y amarillo y un fragmento que simulaba una piedra ornamental) crearía un conjunto elegante y luminoso, proporcionando a ese espacio una notable distinción (cfr. García Bueno, 2015a: 213-214, 221; 2015c: 139-144). Es el único mosaico figurativo conservado ${ }^{2}$ procedente de Puente de la Olmilla, destacando especialmente por su gran calidad artística y su interés iconográfico. Actualmente se halla expuesto en el Museo Provincial de Ciudad Real.

\section{DESCRIPCIÓN DEL MOSAICO}

El pavimento musivo apareció a unos $40 \mathrm{~cm}$ bajo el nivel de superficie. Enlazaba con las paredes por medio de una banda de teselas rojas de cerámica cuyo tamaño oscila entre 1,5 y $2,5 \mathrm{~cm}$ de lado.

El campo de la alfombra, acotado por un rectángulo inscrito en otro, está delimitado por un elaborado festón perimetral de $40 \mathrm{~cm}$ de ancho, cuya gama cromática reúne los tonos verde oliva, rojo terracota, negro azulado, ocre, blanco crema y marrón castaño ${ }^{3}$. Las cuatro esquinas de esta franja rectangular incluyen otros tantos cuadrados apoyados sobre la punta, perfilados por dos hileras de teselas negras y

2. Al Sureste de la habitación 2, en la n. ${ }^{\circ} 4$ (véase Fig. 11) hubo originariamente un mosaico pavimental decorado con una alegoría de los Cuatro Vientos, que lamentablemente fue destruido algún tiempo después de su descubrimiento (Puig y Montanya, 1977: 1-2; García Bueno, 2016: 352-357).

3. Como es habitual en la musivaria romana, para elaborar las teselas de este mosaico se utilizaron piedras locales y material cerámico, excepto en algunas de los emblemas, realizadas con pasta vítrea, con el propósito de introducir tonalidades que no suelen encontrarse entre las materias primas naturales, al menos no en el entorno de la comarca de Albaladejo. Así, se empleó la pizarra en la manufactura de las teselas negro azuladas y verdosas, el barro cocido en las de color terracota y teselas calcáreas (diversos tipos de calizas micríticas) en las de tonos marrón y blanco crema. 


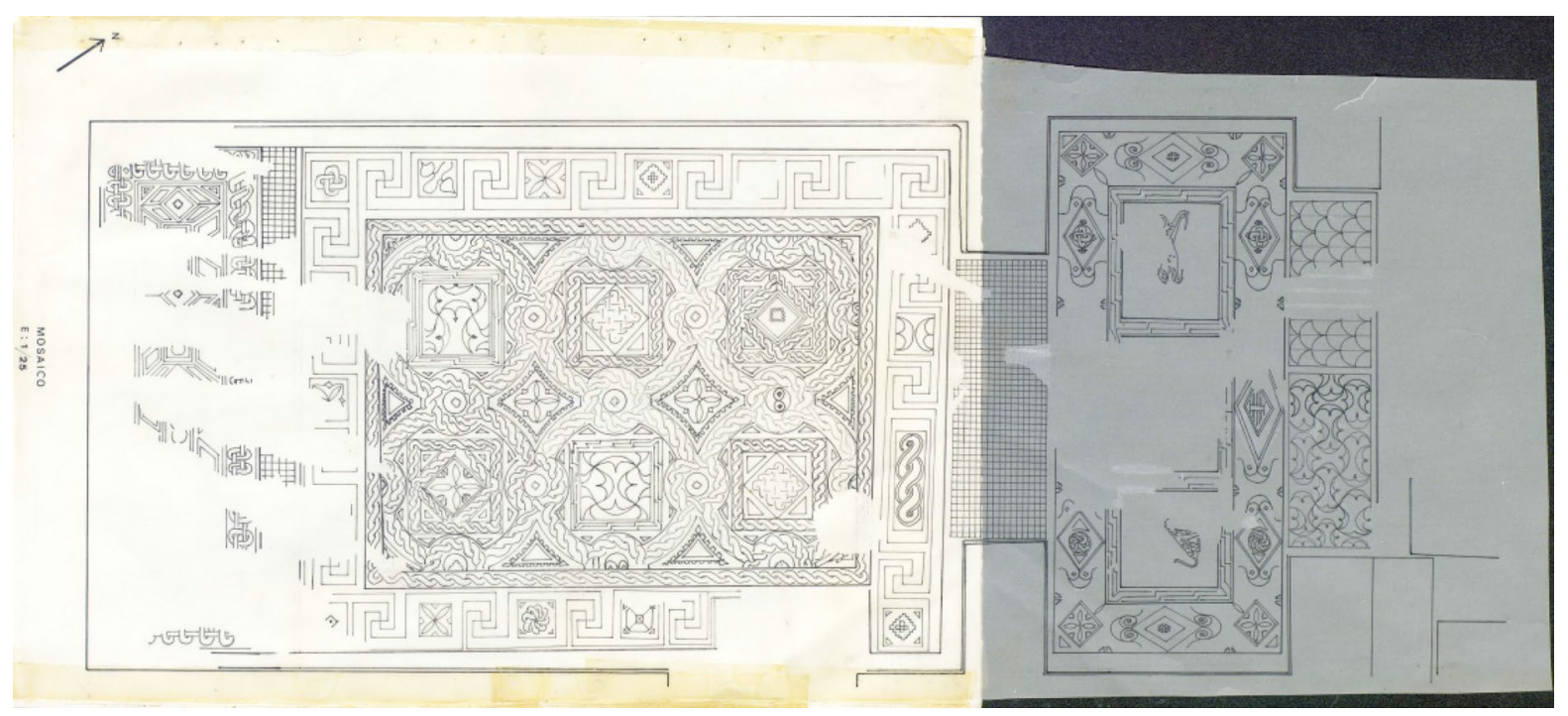

Figura 3: Dibujo original de los mosaicos de la habitaciones n. 1 y 2. Dib.: Puig y Montanya (Archivo General de la Administración, fondo 109.2)

respectivamente enlazados con los cuatro vértices de la orla de enmarque interior mediante una hoja lanceolada en ocre, verde o rojo. Cada uno de esos cuadrados apuntados comprende una roseta tetrapétala en rojo y verde (con alternancia cromática rotativa). Intercalados entre los cuatro pétalos en aspa de este motivo floral, pequeños triángulos dentellados en blanco, rojo y negro se yuxtaponen interiormente a los lados del cuadrado (las dimensiones de los situados a la derecha son 31 x $34 \mathrm{~cm}$ y las de los cuadrados de la izquierda, $31 \times 31,5 \mathrm{~cm}$ ). Asimismo, para rellenar las escuadras de este rectángulo se han introducido sendos triángulos equiláteros en rojo, verde u ocre. Estos elementos se combinan con siete grandes rombos horizontales (originariamente serían ocho, pero uno de ellos, el del centro de la banda superior, se ha perdido, como buena parte del área central del lienzo), rematados por peltas en ambos extremos del eje mayor. Los rombos contienen temas distintos que se articulan de la siguiente manera (de derecha a izquierda, desde el punto de vista del espectador): un nudo de Salomón simple, de doble bucle en rojo y negro, ribeteado por un hilo de teselas blancas y envuelto por círculos de teselas negras, complementado por dos pares de pequeños detalles accesorios consistentes en dos medias cruces de Malta tricolores (en rojo, blanco y negro) y dos triángulos, adosados a dicho círculo y encajados en los cuatro ángulos del romboide. A continuación, en medio, un rombo concéntrico que confina una especie de bastón rectangular de color ocre delineado por una fila de teselas negras, cuyas dimensiones son $16,5 \mathrm{~cm}$ de alto $\mathrm{x}$ $5 \mathrm{~cm}$ de ancho. De cada uno de sus lados sobresalen siete apéndices rectos en tonos verde y castaño, siendo el central más largo $(40 \mathrm{~cm})$ y los restantes decrecientes $(19,16 \mathrm{~cm} . .$. , el de arriba es el menor, Fig. 4). Pese a haberse salvado sólo el rombo correspondiente a la serie inferior, cabe deducir que se reproduciría en la superior, siguiendo la ordenación simétrica vigente en todo el diseño.
Por último, un nudo múltiple, de ocho lazos en rojo y negro, contorneados por una hilada de teselas blancas, dentro de un círculo de teselas negras que está ceñido por dos triángulos de base curva (uno rojo y otro ocre). Esta secuencia se repite en el tramo superior de la cenefa, mientras que en ambos laterales de la misma (colindantes con los muros) se incorporan sendos rombos circunscritos, en cuyo centro se aloja una florecilla cruciforme en rojo y negro. Las dos peltas afrontadas entre las que están colocados estos dos últimos rombos se subdividen en dos puntas (Fig. 5), prolongándose unas mediante una línea curva hacia fuera (sus medidas son $42 \mathrm{~cm}$ de largo x 29,5 cm de ancho) y las otras se ondulan en dos volutas que se convierten en los tallos de flores geométricas (de $32 / 34 \mathrm{~cm}$ de largo), mientras que las de los restantes rombos miden unos $30 / 35 \mathrm{~cm}$ de alto y son de otro tipo: las puntas, de 44 $\mathrm{cm}$ de altura máxima, se alargan inclinándose hacia fuera, hasta tocar ambas líneas de la banda de demarcación, pero no están terminadas en espirales, sino que los intervalos de la curvatura de los arcos están cargados con pequeños cuadrados dentellados policromos.

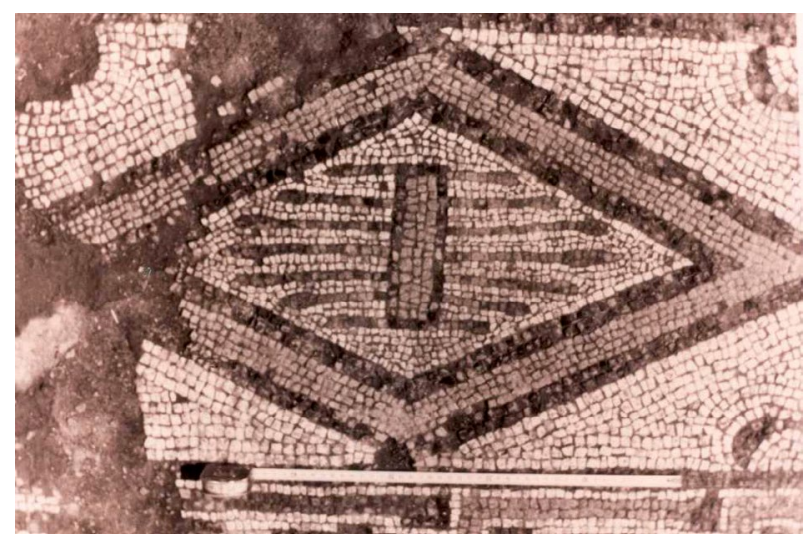

Figura 4: Detalle de uno de los rombos de la orla. Foto: Puig y Montanya (Museo Provincial de Ciudad Real). 


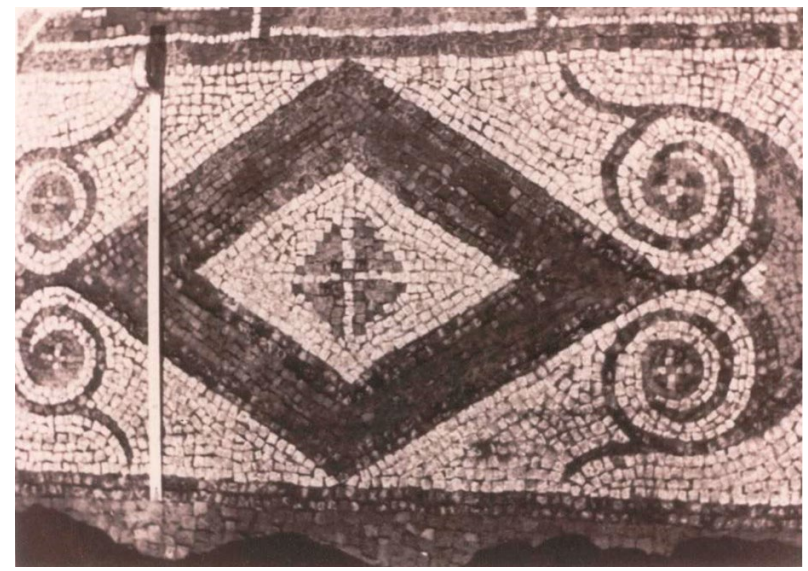

Figura 5: Detalle de las peltas afrontadas y rombo con cruz de Malta. Foto: Puig y Montanya (Museo Provincial de Ciudad Real).

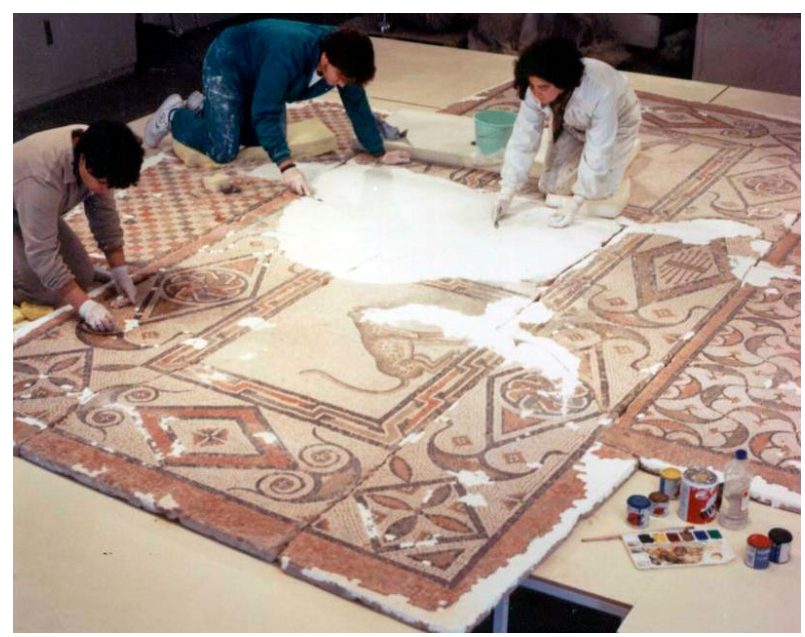

Figura 6: Mosaico de la habitación n. ${ }^{\circ}$ 2. Foto: Museo Provincial de Ciudad Real.

Las peltas funcionan como elemento de conexión de los motivos geométricos, que están organizados con una pauta simétrica, como ya hemos señalado. Se interpone una pelta vertical entre el rombo y los cuadrados alternos de los extremos cortos; asimismo, se dispone en los ejes longitudinales una pareja de peltas enfrentadas entre rombo y rombo, sobre los lados de éstos (Fig. 3). El rombo izquierdo mide $82 \mathrm{~cm}$ de largo $\mathrm{x} 42,5 \mathrm{~cm}$ de ancho, el de en medio, $85 \mathrm{~cm}$ de largo $\mathrm{x}$ unos $44 \mathrm{~cm}$ de ancho (hay una pequeña laguna que afecta al ángulo de la derecha) y el de la derecha, 69,5 $\mathrm{cm}$ de largo x $42 \mathrm{~cm}$ de ancho. Están trazados con un doble filete de teselas negras.

A su vez, en los espacios libres, varios pétalos dobles (medias cruces de Malta formadas por dos pequeños triángulos dentellados tangentes) se unen mediante una tesela a los bordes de este ancho cerco exterior.

Los motivos geométricos y vegetales descritos enmarcan una fragmentaria escena compartimentada. Alrededor de toda ella se desenvuelve una greca policroma constituida por unos elementos geométricos mixtilíneos en rojo, verde y ocre, con teselas negras en los ángulos, mediante los que se consigue una simulación de relieve. Están realizados con teselas de aproximadamente $1,2 \mathrm{~cm}$ de lado. Se consiguió así dotar de homogeneidad ornamental al filo de los tres casetones interiores que conforman el campo emblemático (Fig. 6). En sendos paneles laterales, flanqueando el cuadro principal, destacan sobre un fondo blanco dos figuras zoomorfas colocadas de perfil, oponiéndose cara a cara. Se trata de dos leopardos, silueteados por dos hiladas de teselas negras, de aproximadamente un centímetro de lado (algunas miden entre 60 y $80 \mathrm{~mm}$ ), que definen las marcadas líneas de contorno. Se colocaron las teselas blancas del fondo en filas más o menos regulares $\mathrm{y}$, conforme se aproximan a dichas figuras, las ribetean entre tres y siete hileras. La mayoría de las teselas del campo interior miden algo menos de $1 \mathrm{~cm}$ de lado e inclusive las hay de $0,5 / 0,6 \mathrm{~cm}$.

El rectángulo del lado izquierdo mide $72 \times 97,5$ $\mathrm{cm}$. Está orlado por una franja de unos $13-14 \mathrm{~cm}$ de grosor consistente en una serie de líneas quebradas en zig-zag, de colores verde, rojo y ocre. Ese festón de tacos encierra la representación de un felino sedente, en posición rampante, que sustenta la parte anterior de su cuerpo sobre las patas delanteras rectas y separadas. Está parcialmente dañada la zona de la cabeza y también falta la mitad de la extremidad superior izquierda, a causa del crecimiento de algunas raíces, al igual que le había sucedido a la otra figura, con el consecuente perjuicio por el desprendimiento y pérdida de teselas. En su confección se empleó una gama de seis colores (blanco crema, negro azulado, rojo, verde, castaño y ocre, Fig. 7).

El compartimento de la derecha, bordeado por idéntica greca tratada en meandro fraccionado en porciones oblicuas biseladas, tiene unas dimensiones de $69 \times 94 \mathrm{~cm}$. En este cuadro musivo se combinan siete tonalidades distintas (ocre, blanco crema, negro azulado, verde, castaño, rojo y azul), con las que se obtiene una escena de gran belleza y dinamismo, logrando conferir al dibujo una sensación de profundidad al jugar con la paleta cromática, pues se suceden filas de teselas rojas, ocres, verdosas..., de entre 0,2 y $0,7 \mathrm{~cm}$.

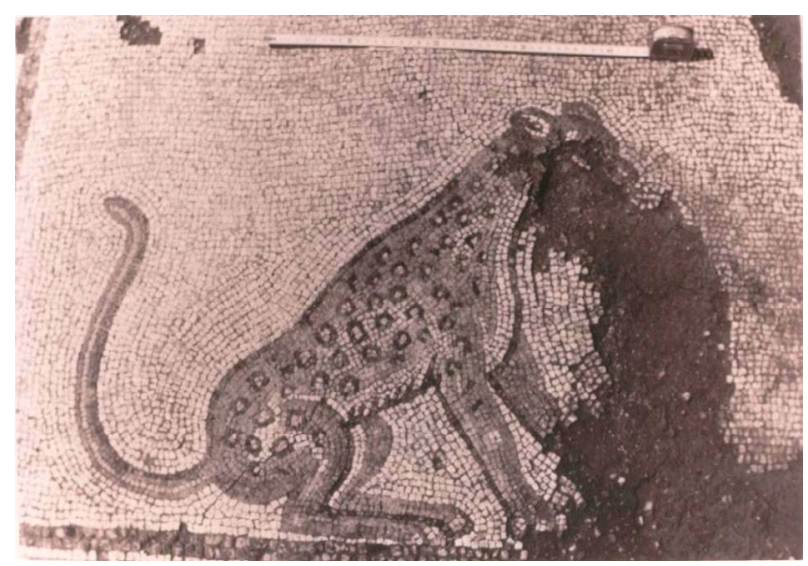

Figura 7: Detalle del felino sentado. Foto: Puig y Montanya (Museo Provincial de Ciudad Real). 
Varias teselas vidriadas de un intenso color rojo componen la lengua y una tesela vidriada azul de $0,5 \mathrm{~cm}$ da forma al ojo. El artífice de esta obra musiva intenta suscitar una impresión de movimiento mediante unos trazos lineales de teselas de color marrón castaño bajo las patas del animal (uno de ellos se curva alrededor de su pata delantera izquierda, por lo tanto, no parece una indicación de sombra proyectada), que presenta las cuatro extremidades extendidas, con las dos posteriores juntas, para darse así impulso en el salto o carrera. Están sombreadas sendas extremidades derechas, convención utilizada para marcar distintos planos y crear de ese modo la referida ilusión de profundidad. Está deteriorado en la parte del lomo y la mitad de la extremidad delantera derecha, de las que se han perdido algunas teselas por la razón antes expuesta (Fig. 8). Se detecta otro fallo en la cola, levantada para ayudarle a mantener el equilibrio en su veloz movimiento.

En los dos paneles rectangulares donde quedan encuadrados los felinos predomina el color blanco, que contribuye a resaltar los brillantes tonos verde claro y oscuro, el azul y el rojo de las teselas de pasta vítrea con las que, respectivamente, se dibujó el ojo y la boca (estas últimas, al menos, en el leopardo de la derecha, pues no se han conservado en el otro). Las manchas de la piel se consiguieron rodeando dos teselas de color crema con seis o más teselas negro azuladas. El pelaje de ambos animales presenta claroscuros, siendo más claras las zonas del cuello y la parte inferior del cuerpo. Esos contrastes realzan el modelado de las figuras, que en absoluto son planas o acartonadas, por el contrario, fueron tratadas con un estilo naturalista y su elasticidad es igualmente notable. Los detalles anatómicos de ambas fieras están bien marcados. Es considerable la minuciosidad en el detalle, la destreza y el buen arte del musivario ${ }^{4}$.

Destaca por su intensidad gráfica la confrontación visual entre la fiera en pleno salto o carrera, dinámica, y la otra, sentada, en actitud plácida (Fig. 9).

El medallón central fue destruido, por lo que no sabemos qué composición albergaba en su interior, pero, por analogía con otras relaciones narrativas afines, muy usuales en la musivaria romana, podría consistir en una crátera; otra posibilidad es la inserción de una escena de Baco apoyado en el tirso o en un sátiro, tal vez acompañado de otros personajes típicos de su séquito (silenos, ménades, sátiros...), e incluso quizás podría ostentar la imagen del dios, solo (p. ej., en forma de busto), sosteniendo una crátera o un rython en

4. A propósito de los diferentes oficios de quienes intervenían en la elaboración de los mosaicos, la nomenclatura con que se les designaba, formas de producción y otros aspectos de su ejecución material, cfr., entre otros, Bruneau, 1984: 241-272; Balil, 1986: 235-253; Balmelle y Darmon, 1986: 235-253; Ramallo, 1990: 135-180; Lancha, 1994: 119-136; Moreno, 1995: 113-143; Dunbabin, 1999: 269-278; Neira, 2010: 483498; Regueras, 2013: 78-81; Vargas y López Monteagudo, 2014: $127-142$.

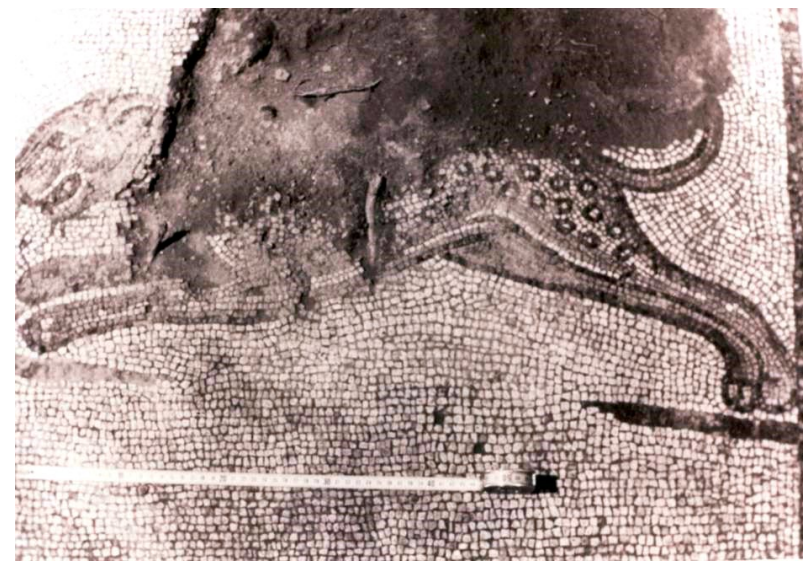

Figura 8: Detalle del felino captado en actitud de correr o saltar (se puede apreciar la existencia de raíces que han dañado el mosaico). Foto: Puig y Montanya (Archivo General de la Administración, fondo 109.2).

la mano u ofreciendo una libación, acaso vertiendo su contenido (Foucher, 1975: 57), o bien llevando otros atributos (como el mencionado tirso), en definitiva, con cualquiera de sus símbolos tradicionales. En un mosaico de Sétif (Argelia), Dionisos es coronado por la Victoria, situada a su lado (Blanchard-Lemée, 2005: 295, fig. 4 a; sobre los otros tipos iconográficos, cfr. Dunbabin, 1971: 52-65; Foucher, 1975: 55-61; Blázquez et al., 1989: 23-24; López Monteagudo et al., 1998: 15-16, con paralelos). El tema se presta a múltiples variantes y, basándonos en paralelismos bien contrastados, cabe suponer que alguna de ellas pudiera haberse desarrollado en el cuadro intermedio del nuestro. Con todo, dado que las dimensiones de éste son $96 \times 71 \mathrm{~cm}$, no parece que haya espacio suficiente para una escena muy compleja. De acuerdo con dicho argumento y con el hecho de que la iconografía más repetidamente utilizada es la de los felinos afrontados a una crátera, esta opción resulta bastante verosímil. No obstante, la rotura del pavimento en ese sector nos impide conocer más detalles de la secuencia decorativa, que sin duda mostraría una unidad temática.

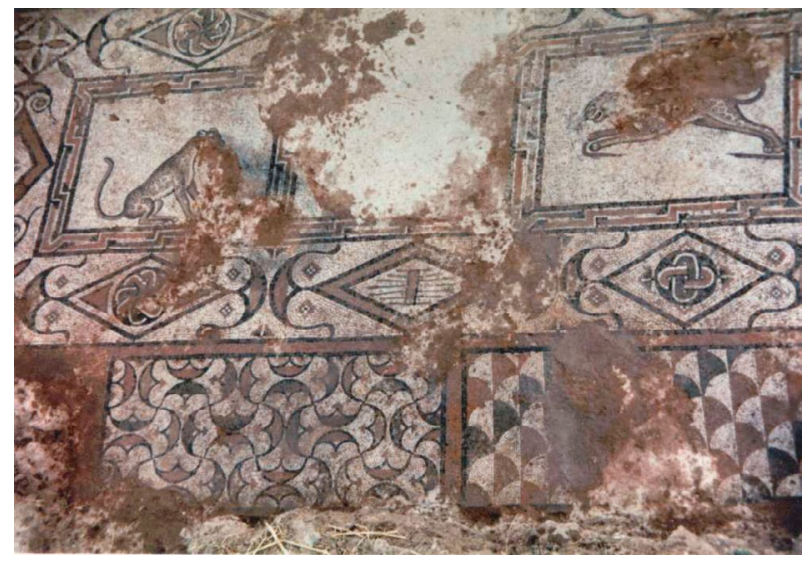

Figura 9: A la izquierda, figura del felino en reposo. A la derecha, felino en movimiento. Foto: Puig y Montanya (Museo Provincial de Ciudad Real). 


\section{ANÁLISIS INTERPRETATIVO DEL MOSAICO}

Como ya hemos avanzado, esta iconografía induce a pensar en un contenido dionisíaco, en cuyo caso entroncaría con el dios vinculado a la difusión de la agricultura y el vino - uno de los productos básicos de la tríada mediterránea-, tan propios del mundo rural en la Antigüedad Tardía (Durán, 2010: 501-526; sobre las Cuatro Estaciones asociadas a motivos dionisíacos, Guardia, 1989: 53-76). Así, O. García Sanz (1994: 329) encuadra en el contexto de la recolección de la vid el mosaico báquico de Sagunto (cfr. Balil, 1979: 21).

Cabe plantear la posibilidad de que este mosaico de Puente de la Olmilla fuera un vehículo de expresión del espíritu pagano del propietario de la villa, que habría dejado también su huella en el registro material del yacimiento mediante una estatuilla en bronce de la diosa Minerva (Fernández Ochoa y Baena del Alcázar, 1992: 337-338) y una terracota probablemente perteneciente a la colección de imágenes veneradas en un lararium $^{5}$ (García Bueno, 2014: 489, 957-958, figs. 281, 503 y 504), a través de los que parece quedar patente. Estos hallazgos refrendarían, a nuestro entender, la teoría interpretativa previamente enunciada. Habida cuenta de todo ello, probablemente no se eligió este tema por puro azar, sino por su simbolismo, para adornar el suelo de uno de los ambientes más señeros de la casa. Tal vez fue específicamente seleccionado para proclamar las creencias religiosas y filosóficas del dominus, en estrecha sintonía con la ideología imperante entre un amplio segmento de los terratenientes durante el Bajo Imperio (cfr. Gorges, 1979: 158-161; Alföldy, 2012: 293-341). Según J.-G. Gorges (1979: 159), la iconografía dionisíaca revela la aspiración a la felicidad prometida a los iniciados del dios, pone de manifiesto sus interrogantes, sus inquietudes religiosas y metafísicas. En esa misma línea coincide con K.M.D. Dunbabin (1978: 182-183), que igualmente atribuye una intencionalidad religiosa a algunos mosaicos de asunto dionisíaco. En cambio, A. Blanco (1952: 16), al referirse a los mosaicos de este género, sostiene que no tenían ningún sutil mensaje implícito: «nada autoriza la sospecha de que sus representaciones hayan tenido jamás un significado religioso trascendental, sino que más bien parecen todos ellos alegres adornos del triclinio o del baño», carentes de «valor simbólico». Sin embargo, los argumentos esgrimidos por K.M.D. Dunbabin y J.-G. Gorges parecen bastante convincentes, inclinándonos a relacionar estos mosaicos, al menos en algunos casos, con lo ultraterreno o con una corriente de pensamiento en boga entre muchos de los latifundistas.

En cuanto al grado de implicación de éstos en la elección del programa decorativo de sus casas, L. Neira (2007: 276-286; 2008: 63-67; 2009: 27-34) reflexiona sobre la contextualización de los mosaicos figurativos

5. Cuyo estudio daremos a conocer en un nuevo trabajo, actualmente en proceso de evaluación. (en especial los de temática mitológica, pero no exclusivamente éstos), que suelen pavimentar un número muy reducido de estancias e incluso a veces una sola ${ }^{6}$, en cuyo caso ese mosaico se destina a una de las dependencias principales, adquiriendo esa excepcionalidad decorativa «su máxima expresión» dentro de un conjunto musivo predominantemente geométrico. Esta autora asume que dicha elección de escenas mitológicas es producto de una decisión consciente, plenamente coherente con la mentalidad e inquietudes de numerosos hacendados. También considera que debe profundizarse en el contenido intrínseco de las imágenes musivas, más allá de su aspecto meramente ornamental, como simples ilustraciones de una realidad cultural, religiosa... O. García Sanz (1994: 328) constata que la finalidad de los mosaicos del ciclo dionisíaco es una cuestión muy debatida, contrastando su enfoque como «objetos utilitariamente decorativos», regidos «por la moda» y circunscritos a «los modelos que un dominus podía ver a su alrededor», con otro que les arroga una carga religiosa. García Sanz ve serios inconvenientes en este último aserto, al entender que los recintos solados con esta clase de mosaicos «no son sagrados, ni aún dentro de una domus, sino atrios, tablina, triclinia, etc.», pudiendo desprenderse de ello su carácter decorativo.

En algunos enclaves norteafricanos, miembros pertenecientes a un nuevo grupo social (possessores, negotiatores, etc.), que habían conseguido amasar importantes fortunas gracias a la producción y comercialización de vino, aceite, trigo u otras mercancías, se hicieron levantar espléndidas mansiones, ornamentadas con valiosos conjuntos musivos. Así, en Thysdrus y en otras ciudades que deben su prosperidad al comercio oleícola (como es el caso de Écija, la antigua colonia Augusta Firma Astigi), se percibe un predominio de los temas báquicos, dejando traslucir «la alegría de vivir» propia de una situación de bonanza (López Monteagudo, 2004: 316). Como pone de relieve esta investigadora, son asiduas las representaciones de Dionisos y de distintos integrantes de su cortejo habitual en los mosaicos encargados por esa élite: «puede decirse que en todas las casas de Thysdrus había una o más escenas de inspiración báquica». El hecho de que esos temas báquicos estén frecuentemente acompañados de elementos marinos es interpretado por H. Slim (1995: 87-119) como una evidencia de la vinculación de Dionisos con el agua, de la que emana la vida, atribuyéndole un carácter alegórico. También este mosaico figurativo de Puente de la Olmilla podría tener alguna connotación de ese cariz para los dueños de la villa o bien éstos pretendían demostrar su identificación con

6. En relación a esa tendencia advertida por L. Neira (2008: 67) de la existencia de un único mosaico figurativo en los programas decorativos de algunas villae, cabe señalar que en la de Puente de la Olmilla se seleccionaron dos temas mitológicos para decorar sendas estancias n. ${ }^{\circ} 2$ y 4 (uno del ciclo dionisíaco y otro con la representación alegórica de los Cuatro Vientos, respectivamente). 
los valores tradicionales romanos y su formación en la cultura clásica a quienes acogían en este espacio doméstico; no obstante, insistimos, sólo podemos formularlo a modo de hipótesis, de lo contrario, simplemente habrían optado por este modelo entre un repertorio de diseños iconográficos muy populares en su época, impuesto, además, por la oferta del mercado, con una variedad disponible más o menos restringida.

Especialistas como A. Balil (1986: 148-151) han revisado la supuesta existencia de bocetos previos, entre los que la clientela haría sus encargos según sus preferencias personales, o si, por el contrario, podrían ser posteriores a la contratación de los mosaicos.

Diversas escenas plasmadas en pavimentos musivos de Hadrumetum reflejan el elevado nivel intelectual de algunos propietarios de suntuosas residencias, enriquecidos con la producción agrícola y ganadera, que después comercializaban (Foucher, 1964: 293; Dunbabin, 1978: 242; Squarciapino, 1987: 193-200; López Monteagudo, 2002: 264-265, láms. 7-8; 2012: 683-686, fig. 11). En todos estos casos parece obvio que escogieron o sugirieron conscientemente la iconografía a desarrollar en las obras musivas que engalanaban sus domus.

Como puntualiza J.M. Blázquez, quien ha estudiado prolijamente los mosaicos hispanos decorados con temas mitológicos, éstos revelan un buen conocimiento de la mitología por parte de los domini, que, a su juicio, elegían expresamente los cartones con las composiciones que se iban a representar (Blázquez, 1987b: 361-403; 2008: 96). Tras repasar los muy diversos temas mitológicos reproducidos en mosaicos de la Península Ibérica, J.M. Blázquez y M.A. Mezquíriz (1985: 47, láms. 28-29, n. ${ }^{\circ}$ 24) concluyen que los possessores hispanos aún mantenían un buen conocimiento de la mitología clásica, similar al existente en otras provincias del Imperio.

Los mosaicos de carácter mitológico y religioso son los que predominan en Hispania, abundando especialmente los de temática dionisíaca, de gran difusión dentro de nuestras fronteras. En el mosaico emeritense de Annius Ponius, fechable hacia el 400 d.C. (Blanco, 1952: 47-50; 1978b: 34, lám. 26 A; García y Bellido, 1965: 201), se aprecia una pérdida o descomposición de los modelos clásicos, percibido por R. Bianchi-Bandinelli (1971: 193) en los mosaicos hispanos de finales del siglo IV (cfr. Balil, 1965: 281; Blázquez y González Navarrete, 1972-74: 419; Blázquez, 1986: 464; 1987a: 25 37). Este último autor coincide con el planteamiento de Bianchi-Bandinelli en lo relativo a que paulatinamente se fueron perdiendo los modelos y las influencias clásicas, pese a que aún pervivieran los temas mitológicos en la musivaria hispana durante la Tardoantigüedad (Blázquez, 1986: 471). Al estar incompleto el tapiz de Puente de la Olmilla, es aventurado aplicarle este concepto del alejamiento paulatino de los cánones clásicos por parte de las producciones peninsulares tardías, un periodo en el que precisamente éstas tuvieron su mayor auge.

Los profundos cambios políticos, socioeconómicos, religiosos y de toda índole acaecidos en esa época tuvieron también su repercusión en el arte, no sólo en el aspecto técnico, sino por propiciar la desaparición de ciertas temáticas, la reelaboración de otras, la introducción de algunas novedosas... (a propósito de la continuidad y las transformaciones graduales de las estructuras del Bajo Imperio romano, contamos con numerosos trabajos de conjunto, remitimos, pues, a la amplia bibliografía compilada por Alföldy, 2012: 293294, notas 654-655).

Otra cuestión nos ofrece nuevas perspectivas de análisis del mosaico que nos ocupa. La destrucción de su panel central se debió presumiblemente a daños producidos en la Antigüedad, pues la documentación gráfica (Fig. 10) y una anotación manuscrita de los arqueólogos en el Diario de excavaciones de 1974 (inédito) nos aportan una información esclarecedora: «el centro se ha perdido, quedando el fallo recubierto con opus caementicium» (a pesar de estar tachado, podemos leer lo siguiente: «fue reparado mediante una especie de cemento antiguo», al que no hacen mención en su posterior publicación, cfr. Puig y Montanya, 1975: 133-143). No creemos que ese dato deba ser interpretado necesariamente como un indicio de la penetración de los iconoclastas hasta este territorio, aunque es sabido que algunas representaciones paganas de la musivaria hispana sufrieron en ocasiones acciones intencionadamente devastadoras, fenómeno ligado a la expansión progresiva del nuevo culto desde las entidades urbanas hasta el medio rural (cfr. Sotomayor, 1982: 639-670; Loring, 1986-1987: 195-204; respecto a la destrucción de mosaicos a manos de los cristianos, particularmente de los báquicos, López Monteagudo y Blázquez, 1990: 353-365).

Un detalle significativo viene al caso: un tema repetitivo en el repertorio musivo de Puente de la Olmilla es el de las esvásticas, que en el mundo romano tenían connotaciones propiciatorias de buena suerte (Campbell, 1994: 293-299, figs. 3-5, 10-11). Se recurre a ellas en la orla del mosaico de la habitación $n^{\circ}{ }^{\circ}$ 2 y en uno de sus tapices complementarios, ubicado al Este; además, cubren todo el campo del pasillo n. ${ }^{\circ}$ 10 en composición continua y en la sección inferior del piso de la habitación $n$. $^{\circ} 15$ se desarrolla un tratamiento distinto de dichas esvásticas (García Bueno, 1994: 102-104, fig. 4, 110-113, fig. 8, respectivamente). Este recurso decorativo de las esvásticas -un símbolo celeste tradicional- se empleó con frecuencia en la musivaria bajoimperial, ya que era considerado un signo talismán. S. Campbell (1994: 293, 296-299, figs. 3-5, 10-11) pone de relieve que la esvástica era elegida por su supuesta cualidad de procurar amparo ante cualquier amenaza, de ahí que este elemento geométrico aparezca repetidamente en los mosaicos romanos desde muy antiguo, como es el caso de algunos de Ostia. A su juicio, no hay duda de los poderes benéficos y positivos invocados mediante este tema en la decoración musiva. Asimismo, el abundante empleo en este elenco musivo de los nudos de Salomón -símbolos apotropaicos- o el de las peltas, a las que los romanos atribuían un sentido profiláctico (Germain, 


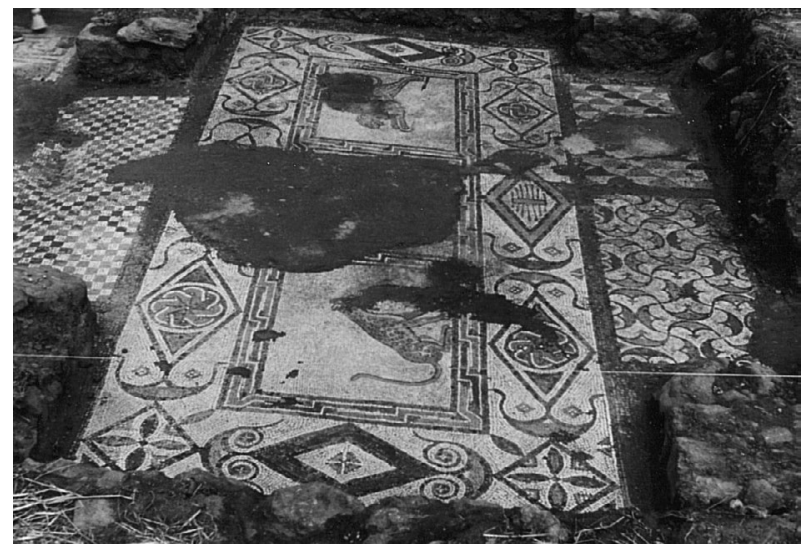

Figura 10: Vista general del mosaico in situ, cuyos desperfectos (incluidos los del cuadro central) estaban cubiertos con opus caementicium. Foto: Puig y Montanya (Archivo General de la Administración, fondo 109.2).

1969: 117), para preservar la casa y a sus habitantes de influencias perniciosas, conjuntamente con las dos figuras (en arcilla y bronce) ya citadas, podrían ser un claro exponente de la pervivencia del paganismo en estas tierras del interior, sin embargo, aunque originariamente dichos elementos fueron símbolos protectores, utilizados para traer bienestar a la casa y a sus usuarios, es factible que durante la baja romanidad ya sólo fueran meros motivos ornamentales y quizás no hablen implícitamente de tal pervivencia. No obstante, en abierta contradicción con esto último, a S. Campbell (1994: 296, fig. 5) le parece improbable poder atribuirle un significado cristiano a una inscripción de San Salvador in Corte (Roma), al tener al final de cada línea motivos con los que los paganos solían invocar buena fortuna y protección, tales como las esvásticas.

A todo ello viene a sumarse que no son perceptibles signos evidentes de violencia deliberada en otros puntos de este yacimiento (cfr. García Bueno, 2015a: 226228; 2015b: 157-158). Avala nuestro supuesto la tesis sustentada por J.M. Blázquez (1986: 470, 475, nota 18, con abundante bibliografía relativa a esta problemática), a cuyo criterio la mayoría de la sociedad hispanorromana de los siglos IV-V era aún pagana, pues, de acuerdo con los postulados de distintas autoridades en la materia, no fue hasta el siglo VII cuando el cristianismo se implantó con fuerza. Arguye J.M. Blázquez que en el Bajo Imperio el cristianismo tenía poca fuerza en Hispania, salvo en la Bética (sobre el cristianismo en el siglo IV, cfr. Blázquez, 1982b: 415-447; VV.AA., 2002). «Al final del siglo IV hay una moda de temas paganos en el arte, que responde a un recrudecimiento del paganismo» (Blázquez, 1981: 88), circunstancia reflejada en la notable representación del thyasos dionisíaco en la musivaria peninsular de esa época. M.A. Mezquíriz y M. Unzu (2005: 999) se hacen eco de estas mismas ideas: las capas altas de la sociedad residentes en el campo, como en general toda la población rural, eran bastante conservadoras y tradicionales, por lo que su cristianización se produciría muy tardíamente (en lo que concierne a la cristianización de la aristocracia hispana, cfr. Palol, 1977-78: 281-300; acerca de la demografía hispana paleocristiana, cfr. Palol, 1967). Las ideologías dominantes se proyectaron en el ámbito de las villae (Bendala y Abad, 2008: 30). J. Hurtado (2005: 367-371) recopila las fuentes disponibles sobre la cristianización de la vecina Carpetania. Rastreándolas, se infiere que, tras el cese de las persecuciones decretado por Constantino, será fundamentalmente en las sedes urbanas donde se concentró el cristianismo durante la segunda mitad del siglo IV y en el V. La existencia en ellas de un cada vez mayor número de cristianos y del clero, cuyo poder iba en aumento, unida a otros factores, provocaron un éxodo al campo de las élites urbanas, que con frecuencia mantendrán allí vivas las mores antiquae (García Bueno, 2000: 198).

En su breve repaso de los espacios sagrados de las villae, J. Hurtado (2013: 155) compendia algunos de los rastros materiales del cristianismo en las villae rústicas (en su pavimentación musiva, piezas cerámicas, etc.), que no son anteriores a mediados del siglo IV y están relacionados siempre con «grupos de escasa relevancia social» (artesanos, miembros de la servidumbre de la casa...). En efecto, a esa centuria pertenecen los primeros testimonios arqueológicos del cristianismo en suelo hispano, que fue irradiando desde un contexto urbano al rural (Chavarría, 2007: 143, sobre las iglesias y las villae: 143-152,158). Se colige de la cultura material de alguna villa de mediados del siglo IV y del V la cristianización de sus domini, aunque abundan todavía los textos religiosos y legales que condenan la connivencia de muchos de ellos en la celebración de rituales paganos. De ello se desprende que el cristianismo no era aún la religión dominante en el siglo $\mathrm{V}$. Conforme se fue afianzando la nueva doctrina, chocaría con el renacimiento de las prácticas mágicas (muy vinculadas a los cultos paganos) que se produjo en el siglo IV (cfr. Salinas, 1990: 240; Torijano, 2000: 544; Hurtado, 2005: 370-371; a propósito de los cristianos en la sociedad tardorromana, cfr. Alföldy, 2012: 294295 , nota 656 , con bibliografía específica).

$\mathrm{Al}$ indagar sobre las personificaciones alegóricas en mosaicos del Oriente y de Hispania, G. López Monteagudo (1997: 349-350) dice que algunos de ellos parecen ser «un manifiesto filosófico de afirmación de los valores helénicos y de rechazo implícito del cristianismo»; se podría hablar, así, de una "exégesis alegórica o simbólica de las imágenes, un 'enigma' iconográfico codificado», cuya lectura abordaría el espectador en función de su nivel cultural. No todos serían espíritus cultivados, capaces de desentrañar las claves para comprender los principios conceptuales que trascendían de esas escenas. Al hilo de este enunciado, no olvidemos el alegato de Amiano Marcelino $(28,4,14)$ en contra de algunos contemporáneos suyos, miembros de la élite, a los que calificaba de incultos e ignorantes.

F. Regueras $(2013: 90,94)$ nos ha brindado su percepción de los llamados «mosaicos del Duero» con escenas mitológicas, que en su mayoría están bien conservados, exceptuando deterioros provocados por 
las labores agrícolas, pues suelen ser daños fortuitos (derrumbes), «en ningún caso resultado de la saña iconoclasta contra 'ídolos' gentiles». Para este investigador, esas escenas formaban parte de una misma cultura de los grupos sociales privilegiados, fueran cristianos o paganos, y «la nueva religión dominante no tuvo el carácter excluyente que luego se arrogó. (...) paganos y cristianos compartían una común ideología visual, que podía prestarse a distintos significados» .

En contraposición a este enfoque, debemos tener presente una nueva contribución al tema realizada por J.M. Blázquez (2008: 108-111), donde examina algunos mosaicos hispanos con temas paganos. En palabras de este autor, entre los que «se picaron por los cristianos» estaría éste de Albaladejo: «Castilla-La Mancha ha dado algún mosaico de tema mitológico, en parte perdido, pues se ha picado, probablemente de manera intencionada, el recuadro central. Quedan dos panteras corriendo hacia el centro (...). El mosaico se halló en la villa romana de Puente de La Olmilla».

En una visión de conjunto de los temas mitológicos en los mosaicos hispanos (Blázquez et al., 1986: 101-161), este grupo de investigadores incide en que muchos de ellos aparentemente están «dañados a propósito, posiblemente por los cristianos», pero eso habría sucedido a partir del siglo VI o, como pronto, de finales del siglo V. Según comentan, «Es probable que estos deterioros en los mosaicos sean recientes (...). Seguramente en el siglo IV prevalecieron entre los latifundistas cristianos unos criterios amplios, en lo referente al arte, como los expresados por Prudencio en su Contra Simmaco I, 502-505» (Blázquez et al., 1986: 133, con bibliografía relativa a estas cuestiones; cfr. también Alföldy, 2012: 293, 295, nota 656, 313$314,394-395,407-408)$. De ello podría deducirse que los cristianos no siempre rompían radicalmente con la religión pagana o que, en ocasiones, su adhesión fue meramente «oficial». L. Neira (2007: 277-286; 2008: 62-77; 2009: 44-48) valora los abundantes hallazgos de mosaicos mitológicos como una probable manifestación del mantenimiento de las antiguas tradiciones del mundo clásico, que habrían pervivido entre muchos de los miembros de ese privilegiado estamento, conscientes de los cambios provocados por la nueva doctrina en el orden instituido y preocupados por su alteración, al intuir un cierto «ataque» hacia el mismo. A su juicio, son escasos los ejemplos de simples motivos de repertorio, carentes de algún significado religioso o ideológico para los domini. Disiente así de lo propugnado por otras teorías, basadas prioritariamente en fuentes literarias, más en la línea de dar cuenta del gran avance de la propagación del cristianismo en nuestra Península, pareciendo minimizar la importancia del alto porcentaje de temas mitológicos y símbolos paganos incluidos en mosaicos figurativos bajoimperiales, que quedarían constreñidos a lo puramente ornamental, sin más.

Como sospecha esta autora, el ascenso gradual del cristianismo pudo desencadenar la reacción de algunos de esos comanditarios, firmes defensores de los principios establecidos, quienes estarían demostrando su fidelidad hacia éstos mediante esas representaciones musivarias, mientras que, por otro lado, de ciertos detalles de la decoración musiva de sus residencias se infiere la conversión de algunos otros, como el de Carranque y el de Fraga, si bien esto lleva a dicha investigadora a abordar un último asunto: en el caso de haber heredado sus haciendas, algunos de los domini conversos, como los acabados de citar, posiblemente habrían resuelto renovar parcialmente el programa ornamental originario de sus viviendas (adaptándolo, rehuyendo la figuración humana en él..., cfr. Fernández Castro, 1982; Chavarría, 2006: 25-26), en tanto que otros, quizás, optaron por conservarlo.

Al hilo de estas últimas consideraciones, retornando a una hipotética destrucción intencionada del emblema musivo central de la habitación $n .^{\circ} 2$, ciertamente ésta no se aviene bien con ese contexto de aparente abandono pacífico del lugar, suscitándonos una duda que deja en el aire lo expuesto hasta aquí, pero tampoco podemos descartar que hubiera sido «picado» (usando la terminología de J.M. Blázquez, vid. supra) por voluntad del dominus en la fase final de uso de la villa de Puente de la Olmilla, pese a no haber constancia arqueológica o algún otro tipo de prueba inequívoca de una posible cristianización de su propietario, ¿o podría ser precisamente ese «cemento antiguo» con el que se cubrió el cuadro «perdido» susceptible de ser interpretado en ese sentido, esto es, materializaría explícitamente su transformación religiosa o la de un nuevo dueño de la villa?, en cuyo caso, si había en medio una representación de Dionisos (ya fuere solo o con otros personajes de su cortejo), en vez de decidir repavimentar toda la habitación, habría solventado el problema de forma menos costosa, rompiendo esa zona del mosaico y rellenándola con argamasa, aunque no es la única afectada, pues la rotura se extiende por el tramo contiguo de la orla de enmarque. De ser así, huelga decir que tanto si este mosaico dionisíaco tuvo realmente en el pasado alguna implicación simbólica para quien promovió su elaboración, como si no, esa iconografía estaría en desacuerdo con su supuesta nueva fe. Por otra parte, bien pudo ocurrir, sencillamente, que se hubiera deteriorado con los años esa porción central del pavimento, por donde sería más frecuente el tránsito hacia la habitación 1, haciendo necesaria una reparación, como se hizo en otros puntos del área solada con mosaicos geométricos, afectados por el desgaste natural con el paso del tiempo y enmendados igualmente con mortero de cal (García Bueno, 2015a: 226; 2015c: figs. 9, 15, 16 y 18). Esta última explicación sería más coherente con la presencia de una estatuilla de Minerva, una figurilla con la imagen de una antepasada o una divinidad y un posible larario (en la habitación n. ${ }^{\circ}$ 15, cfr. García Bueno, 2015a: 212-213, fig. 9; 2015c: 127-133, figs. 2 y 11).

En cuanto a los leopardos aquí representados, según explican sus excavadores, «los fallos en las figuras son debidos a raíces que han estropeado el mosaico» (Puig y Montanya, 1975: 139). 


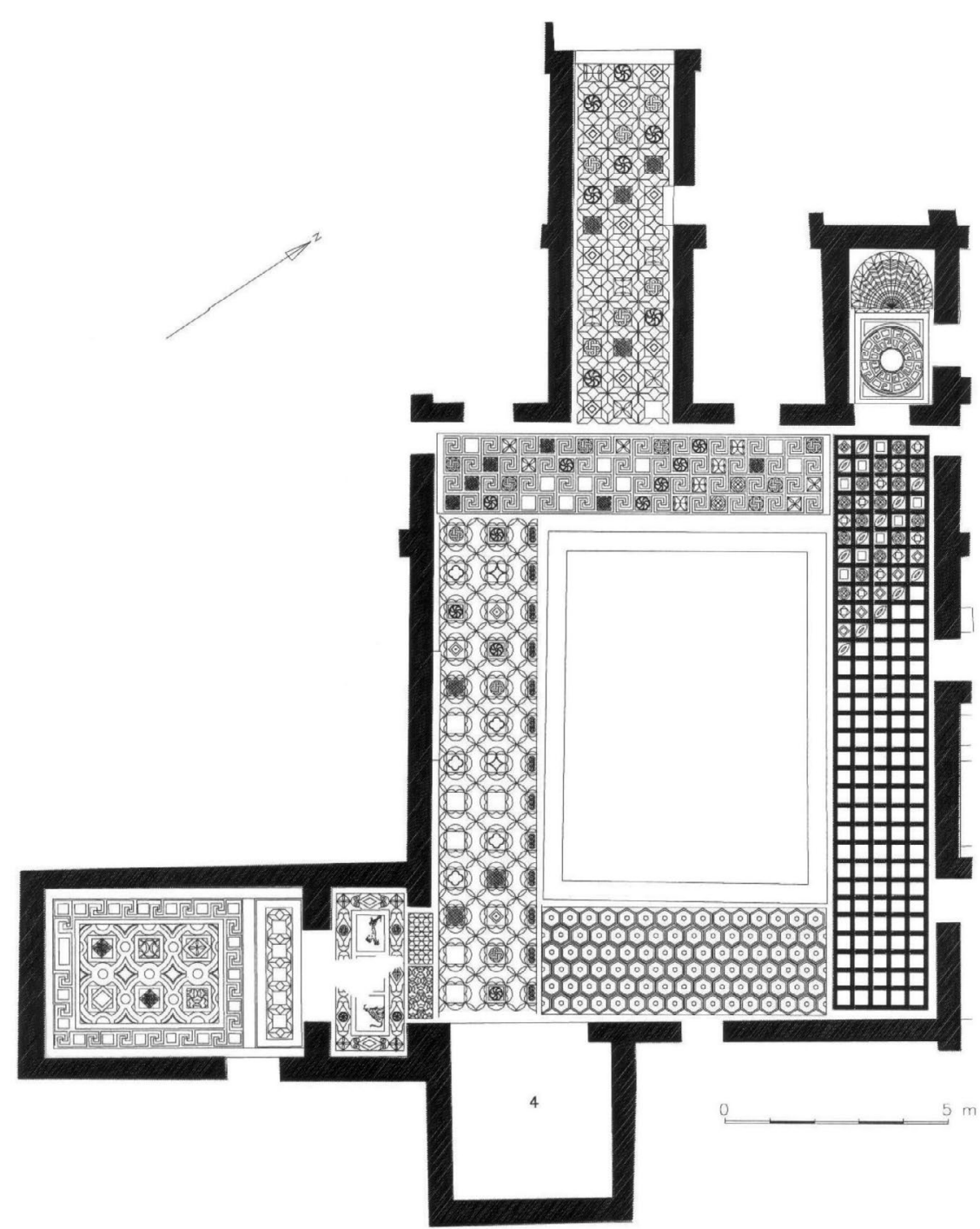

Figura 11: Decoración musiva de la villa. Dib.: García Bueno.

En otro orden de cosas, es de reseñar que las figuras del emblema están orientadas hacia su entrada, como pretendiendo que no pasaran desapercibidas a los ojos de quienes transitaran por allí, en consecuencia, se cuidó que su disposición se adaptara al punto de vista del espectador, quien lo contemplaría al acceder desde el peristilo a la habitación $n .^{\circ} 1$, como invitando así a recorrerla (Fig. 11). Desde esa perspectiva se divisa todo el conjunto pavimental de los dos ambientes consecutivos n. ${ }^{\circ} 1$ y 2 (Fig. 12).

$\mathrm{Su}$ orientación hacia la colindante galería de circulación seguramente pretendía también dar visibilidad a esta escena de cara a quienes se dirigieran a la vecina habitación $\mathrm{n}^{\circ}{ }^{4}$, posiblemente la sala de mayor alcurnia (García Bueno, 2015a: 214; 2015c: 137-139; 2016 : 356-357). Se exponía así, no sólo ante los ojos de los moradores de la villa, sino también de sus visitantes. Es habitual que se fijara la posición de quien miraba el mosaico creando «una única perspectiva privilegiada en toda la estancia», mediante «la ubicación de un grupo figurativo visible sólo desde uno de los lados» de la misma, particularmente en las cámaras localizadas en el interior, al fondo de la vivienda, en los triclinia, cubicula, oeci, etc. (Mañas, 2007-2008: 101). Por lo que atañe a la iconografía musiva dionisíaca, I. Mañas (2007-2008: 106, 112) explica su reiterada presencia en ese tipo de ámbitos domésticos, al propiciar este dios la prosperidad, además de su conexión con una costumbre romana de gran relevancia social, el banquete, siendo considerada dicha iconografía muy apropiada para las salas donde se llevaba a cabo esa práctica social introducida en todo el mundo romanizado. En numerosos pavimentos musivos triclinares se desarrolla el imaginario dionisíaco, proyectando un mensaje concerniente a la ebriedad, estado relacionado con el dios del vino (acerca de las representaciones del convivium, cfr. Dunbabin, 2003). Sin embargo, algunos mosaicos báquicos decoran habitaciones dedicadas a otras actividades (p. ej., en la villa de La Malena es el oecus el que está solado con un mosaico dionisíaco, cfr. Royo, 2001: 46-57), por consiguiente, no se puede vincular de manera exclusiva y automática determinados temas con ciertos espacios de funcionalidad concreta. 


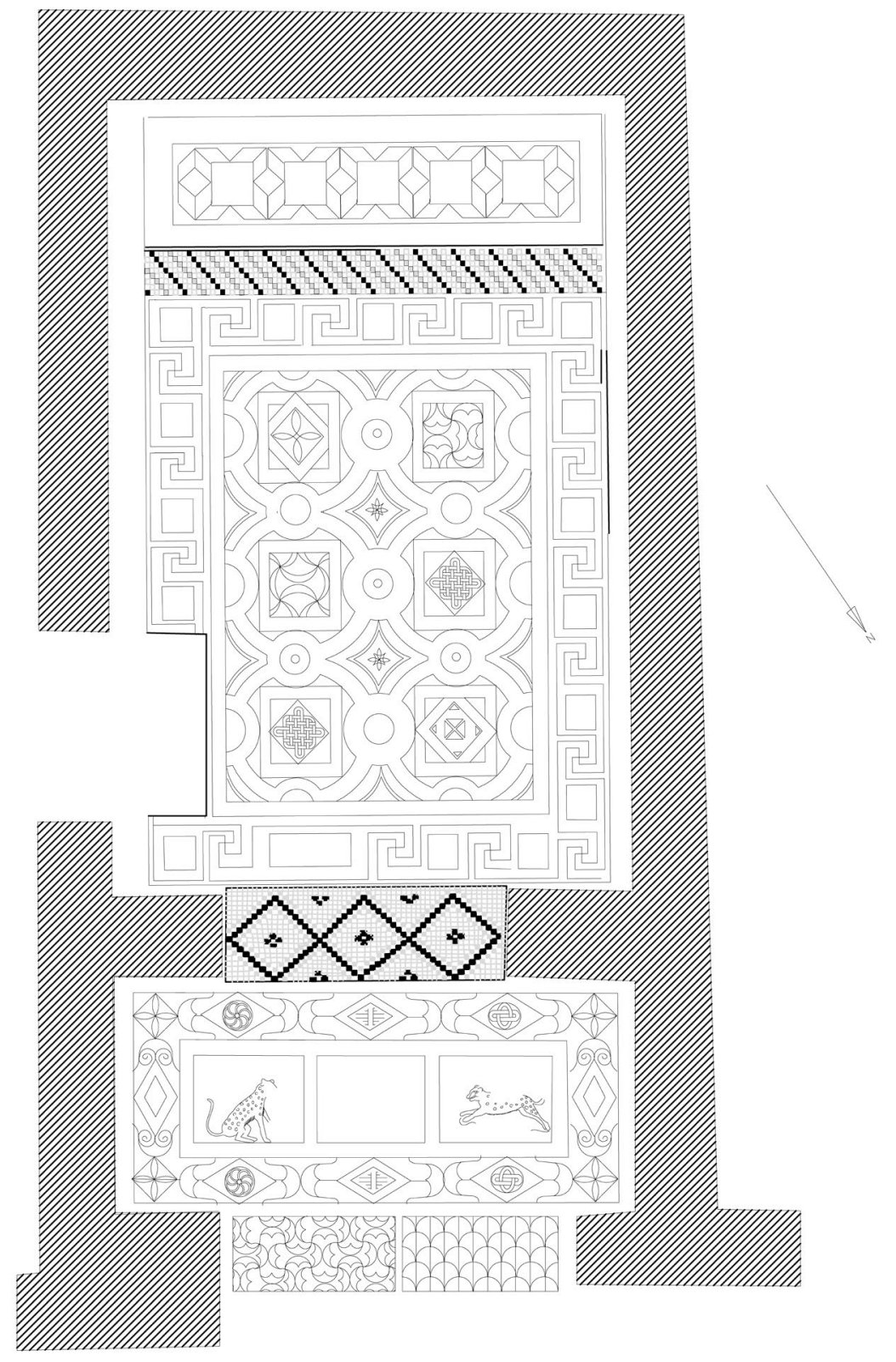

Figura 12: Restitución de los pavimentos musivos de las habitaciones 1 y 2. Dib.: García Bueno.

\section{PARALELISMOS Y ADSCRIPCIÓN CRONOLÓ- GICA DEL MOSAICO}

A los paralelismos aportados por J.M. Blázquez (1982c: 30; 1984: 78) añadimos algunos otros, por nuestra parte. Todos ellos nos permiten seguir el amplio recorrido geográfico de este tema, en diversidad de composiciones.

Felinos afrontados, flanqueando una crátera, se reproducen en un buen número de mosaicos, como uno de Saint-Paul-Trois-Châteaux (Lavagne, 1979: lám. LXII, n. ${ }^{\circ}$ 118), el de Nîmes (Balmelle et al., 1999: 631, pl. CCXXXII), otro de Cerdeña (Angiolillo, 1981: lám. XLII, n. ${ }^{\circ}$ 65), el de la Catedral de Apolonia, del siglo VI (Farioli, 1975: 212, fig. 110), dos de Halicarnaso (Hinks, 1933: fig. 155, n. ${ }^{\circ}$ 540) y uno de Sheikh Zouède (Sinaí, Egipto), muy tardío (fechado entre mediados del siglo IV y mediados del V), donde se representa un felino con las patas delanteras apoyadas en una crátera (Carandini, 1962: lám. C,1; Blázquez y Ortego, 1983: 46; Ovadiah et al., 1991: 181-191; López Monteagudo, 1999: 46-47, fig. 6). Las panteras corriendo hacia una crátera en un mosaico británico de Rudston también son parangonables con la iconografía del de Puente de la Olmilla (Toynbee, 1964: 287). En un pavimento musivo de Cherchel (Argelia), con una cronología de fines del siglo III o incluso algo posterior, uno de los dos felinos que arrastran la carroza del dios bebe en una crátera (Foucher, 1975: 60, lám. XXII, 2). En un mosaico de Hadrumetum, de época severiana, puede verse en primer plano un leopardo bebiendo de un vaso, delante del carro de Dionisos tirado por varios felinos (Foucher, 1975: 58-59, lám. XXI, 1; 1964: 216, nota 805). En un ejemplar de Constantina (Cirta) 
aparece igualmente un leopardo bebiendo de una crátera (Dunbabin, 1978: 178, 255, lám. LXVIII, 174). Asimismo, se le ha atribuido un carácter dionisiaco a una pantera plasmada en actitud de caminar en un mosaico de Sousse, del siglo II, procedente de la Casa de Sorothus y conservado en el Museo de la Marina de París (Foucher, 1960: 53, lám. XXVI a, Inv. Sousse 57.110, lám. XXVI; López Monteagudo, 2002: 262, lám. 12). En un pavimento de la Casa de la Procesión báquica de El Djem, un leopardo avanza al final del cortejo (Dunbabin, 1978: 175-176, 260, lám. LXIX, 175), similar a los que aparecen en sendos extremos de un mosaico de temática dionisíaca de Thysdrus, de las postrimerías del siglo III (Foucher, 1975: 59, lám. XXI, 2), cada uno de ellos encaminándose hacia una crátera, aunque en el conservado en El Bardo están contrapuestos en los laterales, a diferencia de los de Puente de la Olmilla, situados uno frente al otro. En un mosaico de Saint-Romain-en Gal, Dionisos es el eje central de una escena en la que varias panteras se dirigen hacia él -incluidas en dos cuadros laterales, como en el mosaico de Albaladejo-, composición a la que quizás se asemejaría la de éste. Son notorias las afinidades que presenta con el de Puente de la Olmilla un leopardo que salta o corre, con Dionisos a su espalda, en un pavimento de la Casa I,1 de Pella, fechado en el siglo IV (Dunbabin, 1999: 10, 12, fig. 10). En otro pavimento descubierto en Hadrumetum, de finales del siglo II, Dionisos cabalga sobre una pantera (López Monteagudo, 2002: 265); la misma postura (montado sobre un león, un tigre, una pantera...) adopta en varios mosaicos de El Djem (Dunbabin, 1978: 175-176, 260-261, lám. LXIX, 175177) y en uno que tapiza la habitación E de la Casa de las Máscaras, en Delos (130-188 d.C.), donde Dionisos está sentado sobre un leopardo que tiene una de las patas delanteras levantada (Bruneau, 1972: 240-260, figs. 182-183; Dunbabin, 1999: 37, fig. 38). Además, podemos citar un mosaico de Esparta, donde también se representan panteras afrontadas, otro de San Antioco (Sulci, Italia), datado en el siglo II, en el que éstas saltan sobre una crátera (Blázquez, 1984: 78), varios ejemplares ostienses, como el de las Termas de Cisiari, el del Horrea Epagathiana et Epaphroditiana, con felinos captados al saltar o caminar. En un pavimento de la Schola del Traiano, un leopardo con las patas delanteras extendidas está iniciando el salto o carrera (Becatti, 1961: láms. XC, n. ${ }^{\circ}$ 62, XCI-XCII, n. ${ }^{\circ} 18$, XCVI, n. ${ }^{\text {o }}$ 379), al modo del nuestro. Un mosaico dionisíaco de Colonia exhibe la figura de un leopardo (que aparenta ir caminando), enmarcado por un cuadrado (Parlasca, 1959: 77, lám. 74,1), a la manera de los de Puente de la Olmilla, y en un ejemplar de Tréveris se puede contemplar otro (Parlasca, 1959: 42, lám. 47,2).

En suelo hispano, uno de los paralelos geográfica y estilísticamente más cercanos se encuentra en el mosaico de Baco de Alcalá de Henares, de finales del siglo IV o principios del $\mathrm{V}$, con dos leopardos saltando sobre una crátera colocada entre ambos, que tienen una apariencia muy afín al del panel derecho del mosaico estudiado
(Fernández-Galiano, 1975: 921; 1984a: 148-186, fig. 10, láms. LXXXII-LXXXIII, LXXXV-LXXXVIII, XCI-XCII; Blázquez, 1984: 78, fig. 7; Blázquez et al., 1989: 21-26, fig. 7, láms. 11 y 36, n. ${ }^{\circ}$ 2). Cabe mencionar algunos otros, cuyas concomitancias son evidentes, como el de la calle Masona de Mérida, cronológicamente adscrito a la segunda mitad del siglo IV (Blanco, 1978b: 45, lám. 79 A, n. ${ }^{\circ}$ 43; Guardia, 1992: fig. 93; López Monteagudo, 1999: 53-54, figs. 15-16). En este mosaico dionisíaco emeritense se plasma la carrera o salto de un leopardo, cuya iconografía ofrece un parentesco notable con la del felino que contiene el recuadro derecho del mosaico objeto de nuestra atención, variando, entre otros detalles, en que aquél se dirige hacia una crátera en sentido contrario al de Puente de la Olmilla. En el de Annius Ponius, datado en torno al año 400, un leopardo vuelve la cabeza para beber el líquido derramado del jarro que Baco lleva en una de sus manos (Blanco, 1978b: 34, láms. 26 y $27 \mathrm{~A}$, n. $\left.^{\circ} 15\right)$. En uno de la Casa de Hylas, de Itálica (García y Bellido, 1960), y en otro de Quintanilla de la Cueza (García Guinea, 1977: 187-191) se repite el tema de los felinos afrontados a una crátera. En dos medallones de un fragmento musivo de la colección de la Casa de la Condesa de Lebrija en Sevilla, remontable al siglo II d.C., Baco está acompañado de una pantera (Blanco, 1978a: 39, lám. 41,2, n. $\left.{ }^{\circ} 17 \mathrm{~B}\right)$. Otra pantera y un tigre báquico que posa su pata en una crátera, aparecen en el mosaico de Ganímedes, de esa misma colección, fechado hacia el 150 d.C. (Blanco, 1978a: 28-29, lám. 14, n. ${ }^{\circ}$ 4). El mosaico con bustos báquicos de Itálica está decorado con diferentes felinos (Blanco, 1978a: 27-28, láms. 1113, n. $\left.{ }^{\circ} 3\right)$. Dionisos niño monta una pantera en un mosaico de Sagunto (Balil, 1979: 21; García Sanz, 1994: 329), al igual que en otro italicense de principios del siglo III d.C., conservado en la colección de la Casa de la Condesa de Lebrija (Blanco, 1978a: 39, lám. 42, n. ${ }^{\circ}$ 18). A. Blanco (1978a: 39) refiere que los componentes del ciclo báquico presentan «sensibles diferencias» a la vez que «rasgos comunes». En el mosaico de Orfeo, de Zaragoza, un leopardo está acompañado de un león, un tigre... (Blanco, 1952: 36; Guardia, 1992: fig. 23). En una pieza procedente de la estación de ferrocarril de Mérida tenemos otro modelo de leopardo (Guardia, 1992: fig. 95). En Écija hay dos mosaicos de temática báquica-Dionisos en el carro-, que incluyen en la orla el tema de los felinos: leopardo y palomas convergen hacia una crátera en el mosaico del Triunfo de Baco (Romo, 2003: 93-95; Vargas, 2014: 47-48, lám. 37; Vargas, López Monteagudo y García-Dils, 2017: 85-86, figs. 75-76, n. ${ }^{\circ} 42$ ); en el otro, dos felinos afrontados, sin ninguna figura o crátera intermedia (López Monteagudo et al.: 1999, 516, lám. CLXXII-1; Vargas, 2014: 29-30, lám. 10; Vargas, López Monteagudo y GarcíaDils, 2017: 114-115, fig. 113, n. ${ }^{\circ}$ 67). Los dos tigres representados en este último ejemplar pertenecen al mismo tipo icónico que el del lado derecho del nuestro.

Al margen de estas creaciones suntuarias que son los mosaicos, hallamos el tema del felino bebiendo de 
un kantharos en sarcófagos de contenido dionisíaco, como uno del Museo Chiaramonti, Vaticano, y en otro de Hever Castle, entre muchos otros (Turcan, 1966: 441-472; San Nicolás, 1994: 405-420, con una completa bibliografía). De manera similar, un freno de caballo descubierto en Conimbriga está decorado con una crátera entre panteras rampantes (Blázquez, 1984: 78, nota 52). Las representaciones de felinos asociados a temas dionisíacos en las más diversas manifestaciones artísticas del mundo romano son, por tanto, muy abundantes, pero particularmente en la musivaria (respecto a la del Norte de África, cfr. Dunbabin, 1971: 52-65; 1978: 173-187).

Así pues, el formato de este mosaico, con la contraposición de dos felinos, no es novedoso. Existe, además, una serie iconográfica muy variada dentro del género báquico, pudiendo encontrarse a veces en ella analogías con las figuras del mosaico de Albaladejo. Diversidad de felinos tiran del carro triunfal del dios en numerosos pavimentos de mosaico (Román, 1914: 117-120; Blanco, 1952: 13-14, 29-34, fig. 14; Parlasca, 1959: 40, láms. 40,1; 41,4; una selección bibliográfica puede consultarse en Foucher, 1960: Inv. Sousse 57099, lám. XXIII; específicamente sobre este tipo de escena, cfr. Becatti, 1961: lám. LXXXIII, n. ${ }^{\circ} 377$; Foucher, 1975: 58-60, láms. XXI, 1-2, XXII, 1-2, 6061, XXIV, 1-4; Dunbabin, 1978: 40, 46-47, 66, 259, lám. X, 20, 181-182, 269, lám. LXXI, 181-182; Fernández Castro, 1978: 324; Blázquez, 1980: 125-162; 1981: 72-73, lám. 60, n. ${ }^{\circ}$ 52; 1982a: 13-19, láms. 1-2, 38-39, n. ${ }^{\circ}$ 1; Fernández-Galiano, 1984a: 11-89, fig. 1, láms. I-LVIII; Mezquíriz, 1986: 238-242, 248-249, lám. 3; González Cordero et al., 1990: 322-324, figs. 3 y 4; Guardia, 1992: figs. 109, 118; San Nicolás, 1994: 1296; López Monteagudo, 1999: 36-40, figs. 1-2, 1214; Blanchard-Lemée, 2005: 295, fig. 4 a). En muchos de esos lienzos musivos aparecen leopardos, algunos de ellos situados en los flancos, como en el nuestro.

Para no alargarnos demasiado, no nos extenderemos más en esta enumeración, pese a que nuestro país ha dado otros mosaicos dionisíacos (al respecto, cfr. Blanco, 1952; Blázquez, 1984: 69-96; FernándezGaliano, 1984b: 97-121; García Sanz, 1990: 308-321; 1994: 332, figurando el de Puente de la Olmilla con el n. ${ }^{\circ} 11$ en el cuadro de mosaicos báquicos hispanos; López Monteagudo, 1999: 35-60; Mañas, 2011: 367-380).

En última instancia, el gran número de pavimentos musivos del ciclo báquico estilísticamente similares nos lleva a interpretar como tal el ejemplar de la habitación $n .^{\circ} 2$ de Puente de la Olmilla, dadas las afinidades de sus figuras laterales con las de muchos de los mosaicos dionisíacos citados.

Al estudiar los mosaicos hispanos tardoimperiales, M. Guardia Pons (1992: 382-383) se refiere al que estamos analizando como el de «Panteras y cráteras», pero lo ubica en una villa rural de Almendralejo, en vez de Albaladejo, aunque sí emplaza dicha villa en la provincia de Ciudad Real. No está incluido en el capítulo que dedica a la serie musiva dionisíaca (Guardia,
1992: 351-370), sino en el Apéndice A, donde tan sólo sintetiza muy escuetamente sus dimensiones y la fecha propuesta por sus excavadores (vid. infra).

J.M. Blázquez (1993: 329) hace alusión al mismo como una de las dos representaciones en mosaicos hispanos de «panteras dionisíacas que se dirigen a beber a los cántaros» (la otra es la de Alcalá de Henares; cfr., igualmente, Blázquez, 1984: 78, fig. 15, donde menciona brevemente este ejemplar). Asimismo, O. García Sanz (1994: 332) también utiliza el término de «panteras báquicas» al hablar de éste.

Por lo demás, J.-G. Gorges (1979: 247) apunta que la representación de panteras en mosaicos, «a medio camino entre el tema del thiasos báquico y el de la venatio», es típica de la instalación en el campo de un gran possessor del Bajo Imperio.

En efecto, las imágenes musivas de panteras (o, más propiamente dicho, felinos, por hablar de modo genérico de esta especie animal, cfr., al respecto, Dorigo, 1966: 129) se relacionan tanto con los cartones de thiasos báquicos como con los de venationes norteafricanos. Así, el tipo icónico de los leopardos de Puente de la Olmilla se documenta también en escenas de cacería o de combate con fieras. Sin ánimo de ser exhaustivos, citaremos un pavimento de la Casa de Isguntus, de Hippo Regius, probablemente del 310-330 d.C. (Dunbabin, 1978: 55, 262, lám. XIV, 29; Blázquez, 1994: 1174), o un ejemplar de Khéreddine (Cartago), cuya cronología ronda el 390-410 d.C. (Dunbabin, 1978: 57-58, 62, 144, 253, lám. XVII, 36-37; Blázquez, 1994: 1171-1172), otro de la Casa de Baco, en Djemila (la antigua Cuicul, Argelia), datado a fines del siglo IV o principios del V, con un leopardo en pleno salto (Dunbabin, 1978: 62, 76, 118, 256, lám. XIX, 45; Blázquez, 1994: 1174, 1176; 2012: 80), un segundo ejemplar de Djemila, con un leopardo y otros felinos (Dunbabin, 1978: lám. XXVI, 67), asimismo, aparecen leopardos saltando en dos pavimentos de la Domus Sollertiana, de El Djem, uno de los cuales, el mosaico de Diana y los animales, adscrito al último cuarto del siglo II, fue colocado en el triclinium (Dunbabin, 1978: 66, 259, lám. XXI, 50-51 y 46, 259, lám. X, 20; Blázquez, 1994: 1171, lám. Ia). Tanto en escenas de anfiteatro de Zliten (Libia) como en otras de Thysdrus, unos leopardos participan en el suplicio de damnati ad bestias (Foucher, 1961: 19, figs. XXI-XXII; Romanelli, 1965: 277-278, figs. 2-3). En una pieza del espléndido conjunto musivo de Piazza Armerina pueden verse diversos felinos (Carandini et al., 1982: 178), al igual que en un pavimento de la villa constantiniana de Daphne, en Antioquía (Levi, 1947: II, 248, láms. LVI a y b, LVII a y b, LIX; Cimok, 2000: 216). Un leopardo corre, perseguido por un cazador a caballo, en un mosaico de la villa emeritense de El Hinojal, fechado en el siglo IV (Blanco, 1978b: 51-52, fig. 5, lám. 94 B, n. ${ }^{\circ}$ 64; Guardia, 1992: figs. 96-97). Otros son abatidos en la venatio representada en el oecus de La Olmeda (Palol y Cortes, 1974: 55-61, fig. 20, láms. L-LXXII; Guardia, 1992: figs. 66-71; San Nicolás, 1998: 894-895; Neira, 2011: 
61-62, fig. 8; Regueras, 2013: 91, 94, láms. 59 y 61). En el mosaico de Bellerofonte y la Quimera, de Conimbriga (López Monteagudo, 1990: 204, fig. 4), puede contemplarse la carrera de Bellerofonte, muy parecida a la de uno de los leopardos de Puente de la Olmilla.

Entre los de este listado, los leopardos del ejemplar complutense reseñado previamente en la relación de paralelos son algunas de las figuras de felinos que nos recuerdan más a las del mosaico estudiado (concretamente al animal situado a la derecha). Es probablemente el más allegado al sentido decorativo del nuestro. La datación propuesta abarca un lapso temporal entre finales del siglo IV o comienzos del V (Fernández-Galiano, 1975: 921-928; Blázquez et al., 1989: 21-26, fig. 7, láms. 11 y 36, n. $^{\circ} 2$ ). Por otra parte, es ciertamente significativo que ese referente formal tan parecido al de Albaladejo se halle precisamente en un área geográfica relativamente próxima. Las afinidades que se observan en su imagen visual dan consistencia a la idea de su pertenencia a un mismo contexto musivario y tal vez a una misma comunidad de taller.

Según O. García Sanz (1994: 327), para entender los mosaicos dionisíacos hispanos debe tenerse en cuenta la transmisión que tuvo lugar desde el Norte de África, como se desprende del examen de prototipos y paralelismos, poniendo de manifiesto la participación de Hispania de todas las tendencias artísticas que circulaban por la pars occidentalis del Imperio. Ello se traduce en un tratamiento análogo de algunos temas, p. ej., las representaciones de panteras, las distintas figuraciones de Baco, confinado en medallones (cfr. Fernández-Galiano, 1984a: 161-162, n. ${ }^{\circ}$ 272-278). Sin embargo, se puede abogar por un origen más diversificado de dichas corrientes de influencia, pese a carecerse de certeza sobre las razones que generaron la introducción de variantes a lo largo del tiempo. L. Foucher (1975: 61) propone algunas, que abarcan desde la mera fantasía a las modas de las officinae o los desplazamientos de los equipos de musivarios.

A la vista de los testimonios ofrecidos, el repertorio ornamental del mosaico que nos ocupa presenta numerosos puntos de contacto con el temario de multitud de ejemplares. Sus excavadores nos ofrecen algunos paralelos de los motivos geométricos (Puig y Montanya, 1975: 142), a los que remitimos (asimismo, cfr. Blázquez, 1982c: 29-30, con las referencias bibliográficas correspondientes). Seguidamente añadimos algunos otros ejemplos.

En toda la órbita del Imperio se aplicó abundantemente la pelta a la decoración musiva, un signo utilizado para protegerse ante el infortunio, por lo que se empleó asiduamente en el suelo de las zonas de paso, como era la habitación $n .^{\circ} 2$. La banda perimetral de la alfombra que la cubría, integrada por rombos horizontales en cuyos ángulos extremos hay sendas peltas verticales (cfr. algunas variaciones en Balmelle et alii, 2002: I, 109, lám. 59 b, 221, lám. 145 c, 225, lám. 147 f y 299, lám. $189 \mathrm{~b})$ se documenta en mosaicos ostienses en blanco y negro de la primera mitad del siglo I d.C. (Becatti,
1961: 130, lám. XXX, n. ${ }^{\circ} 255$ y 144-145, 148, lám. CIII, n. ${ }^{\circ}$ 283). Las composiciones de peltas son muy usuales en mosaicos de Pompeya, de Olimpia (Termas de Cladeus), de Corinto y de Lyon (Blake, 1930: 104; Balmelle et alii, 2002: I, 109, lám. 59 b), asimismo, se difundió profusamente en Germania, por ejemplo, en Tréveris (Parlasca, 1959: 8, lám. 15,2, 11, lám. 17,23, 41, lám. 42,2, 46, lám. 48,3 y 58, lám. 57,3-4) y en Fliessem (Parlasca, 1959: 15, lám. 20,2), unas veces flanqueando rombos y otras en forma de ruedas de peltas. Se expandió hasta Britania (Smith, 1975: figs. 5,6), alcanzando con gran éxito Hispania. Peltas afrontadas a cada lado de un rombo son frecuentemente utilizadas en mosaicos emeritenses, como sucede en dos descubiertos en la Casa del Mitreo, respectivamente del siglo II y de las postrimerías de esa misma centuria, o en otro de la calle de Oviedo, del siglo IV (Blanco, 1978b: 39-40, láms. 44 B-45 A, n. ${ }^{\circ} 21,40$, lám. 48 A, n. ${ }^{\circ} 24$ y 33-34, láms. 24 B-25, n. ${ }^{\circ} 14$ ). Volvemos a hallar rombos acabados en dos peltas en uno de los cuatro campos en que se divide el opus tessellatum del lateral oriental del peristilo de la villa de Liédena, concretamente el A 7 (Blázquez y Mezquíriz, 1985: 35, fig. 21, lám. 22, n. ${ }^{\circ} 11$ ), y en una alfombrilla adyacente al panel con las Cuatro Estaciones del mosaico báquico de Alcalá de Henares, de finales del siglo IV o inicios del V (Blázquez, López Monteagudo, Neira y San Nicolás, 1989: 21-26, fig. 7, láms. 8-9, 33, n.o 2) y en la faja que determina un mosaico geométrico de Jumilla (Blázquez, 1982a: 64, fig. 22, n. ${ }^{\circ}$ 56), aunque los rombos carecen de la variada decoración interior del nuestro.

En la Bética, la cenefa de rombos enmarcados por peltas es muy común. La encontramos, entre otros lugares, en la villa romana de la Estación, de Antequera (ss. III-IV) (Vargas, 2016a: 62, láms. 19A-19B), en la villa del Alcaparral (Casariche, Sevilla) (ss. IV-V) (Vargas, 2016a: 53, lám. 13), en dos mosaicos de la villa Cortijo Vila (Alameda, Málaga) (ss. III-IV) (Vargas, 2016a: 56, lám. 16; 58, lám. 17), en la villa de El Arca (Castro del Río, Córdoba) (ss. III-IV) (Vargas, 2016a: 137, lám. 65). En Écija aparece en un mosaico del siglo II (Vargas, 2014: 45, lám. 34; Vargas, López Monteagudo y García-Dils: 2017, fig. 72, n. ${ }^{\circ} 39$ ), en otro del siglo II al III (Vargas, 2014: 56, láms. 47A-47B; Vargas, López Monteagudo y García-Dils, 2017: figs. 98, $100-101$, n. $^{\circ}$ 61) y en un tercero de cronología incierta (Vargas, 2014: 34-35, láms. 18A-18C; Vargas, López Monteagudo y García-Dils, 2017: figs. 24-26, n. ${ }^{\circ}$ 15). En forma muy parecida a la de nuestro ejemplar, el detalle ornamental de los rombos horizontales colocados entre peltas verticales se incluye en el cerco exterior del mosaico de las Cuatro Estaciones de Córdoba, datado en la segunda mitad del siglo IV (Blázquez, 1981: 36-38, láms. 22-23, n. ${ }^{\circ} 19$, con paralelos, entre los que el autor cita precisamente este mosaico de Puente de la Olmilla), de nuevo, en el pavimento de la habitación 4 de la villa cordobesa de Fuente Álamo (San Nicolás, 1994: 1300-1301). Esta autora (San Nicolás, 1994: 1301) considera probable «la existencia de un taller 
musivario o de artistas ejecutores del motivo» en esa zona, cercana a la nuestra. En otro lienzo musivo de esta villa (ss. IV-V) se introduce una variación: un círculo entre rombo y rombo (Vargas, 2016a: 163, láms. 78A-78B; 177, láms. 84A-84B; 2016b: 185-226).

Entre los innumerables ejemplos existentes en nuestro continente, se puede establecer otro paralelismo en la Basílica de Es Fornás de Torelló (Menorca), a la entrada de su ábside rectangular, fechable a mediados del siglo VI (Palol, 1967: fig. 69), que, junto al Palacio de Teodorico en Ravenna (Farioli, 1971: 459, fig. 27), constituyen algunas de las interpretaciones más tardías de este cliché decorativo, lo que evidencia su larga vida. Así pues, este motivo experimentó un inusitado auge en la musivaria romana de los siglos IV-VI d.C., perdurando posteriormente. Por consiguiente, esa cronología tan amplia de la pelta no nos permite utilizarla por sí sola como criterio de datación, pero fue ciertamente uno de los recursos más constantes y repetidos en el arte musivario romano, particularmente en el bajoimperial.

Fue muy popular en el Norte de África, p. ej., en mosaicos de Sabratha, Leptis Magna, Zliten, Cartago, Timgad... (Aurigemma, 1960: 58, láms. 2, 75, 118119 y I, MCMLX; Foucher, 1960: láms. 18, 36).

En lo que respecta a la armoniosa trenza ejecutada a base de líneas quebradas que define el campo emblemático (Fig. 13), logrando de ese modo dar continuidad a los tres casetones centrales, está ampliamente atestiguada tanto en el ámbito peninsular como fuera de nuestras fronteras. Es un elemento decorativo que despertó gran interés entre los musivarios que trabajaron en Hispania. El paralelo más próximo se halla precisamente en otros mosaicos de Puente de la Olmilla: el de la habitación n. ${ }^{\circ} 1$ (Puig y Montanya, 1975: 134-138, 140-141, fig. 2) y, con alguna variante, el del pasillo n. 5 (García Bueno, 1994: 107-108, fig. 6). Se constata su presencia en varios ejemplares emeritenses, p. ej., en uno de la Casa del Mitreo, de finales del siglo II o inicios del III (Blanco, 1978b: 40-41, láms. $49 \mathrm{~A}, 51 \mathrm{~A}$, n. $^{\circ}$ 25) u otro de la Casa del Anfiteatro, datado en el siglo III (Blanco, 1978b: 42, láms. 56 B-58 $\mathrm{A}, 61 \mathrm{~A}, 62 \mathrm{~A}, \mathrm{n}^{\circ}$ 31), en un pavimento de la villa vallisoletana de Prado (Wattenberg, 1962: fig. 1), en otro de Quintana del Marco (León), del siglo IV, donde ciñe octógonos (Blázquez et al., 1993: 33-34, láms. 11 y 31, n. $\left.^{\circ} 19\right)$. Se puede contemplar en un mosaico de Requejo (Zamora), de las postrimerías del siglo IV o del $\mathrm{V}$, donde esa misma cenefa recorre el borde de los cuatro triángulos de las esquinas (Blázquez, 1990: II, 359-368; Regueras, 1991: 167, fig. 2), y en uno de los sectores occidentales del mosaico $\mathrm{C}$ de la habitación n. 5 de Baños de Valdearados (Burgos), remontable a la primera mitad del siglo $\mathrm{V}$ (López Monteagudo et al., 1998: 18-19, fig. 4, n. ${ }^{\circ}$ 3). Tenemos otros términos de comparación en algunos pavimentos de la villa de Los Quintanares (Soria), donde este tema ornamental tuvo una notable incidencia (Blázquez y Ortego, 1983: 22-24, láms. 4-5, n. ${ }^{\circ} 6$ y 8, respectivamente, 24-25, lám. 6, n. ${ }^{9}$, 32-33, lám. 34, n. ${ }^{\circ} 26$ y 27). Se

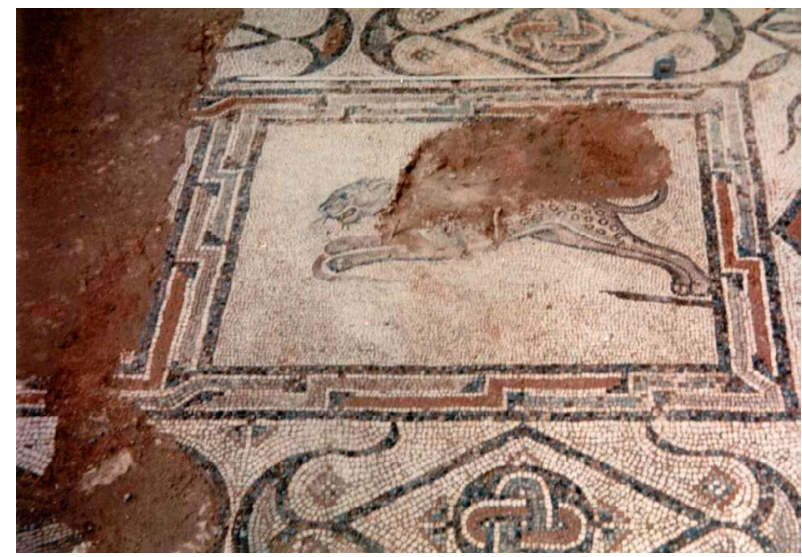

Figura 13: Detalle de la orla periférica y del festón de líneas quebradas en zig-zag. Foto: Puig y Montanya (Museo Provincial de Ciudad Real).

documenta igualmente en la segunda de las orlas que flanquean el tapiz principal del mosaico III de Cuevas de Soria, de mediados del siglo IV (Fernández Castro, 1983: 63-65, fig. 6, n. ${ }^{\circ}$ 55). Una réplica que guarda alguna similitud con dicho arquetipo está acreditada en dos pavimentos de la villa de Santervás del Burgo (Soria), con peculiares variaciones tales como la alternancia de hileras de peltas y coronas, encajadas en círculos en vez de en hexágonos (Ortego, 1965: 87, 89, figs. 8 y 15; Blázquez y Ortego, 1983: 41-42, lám. 14, n. ${ }^{\circ} 37,42-44$, lám. 18, n. ${ }^{\circ} 41$ ). Muy parecido al meandro de esvásticas fraccionadas del mosaico objeto de nuestro estudio es el del interior de los hexágonos de dos ejemplares de Cabra, uno geométrico con nudos de Salomón, de la Casa de Mitra, y el del tapiz inferior del mosaico del Triunfo de Baco (Blázquez, 1981: 50, fig. 19, n. ${ }^{\circ} 31$ D, 102, fig. 32), ambos del siglo III. En el de la cabecera del oecus de la villa navarra de Arellano se utilizó la misma técnica para construir algunas de las figuras geométricas del interior (Mezquíriz, 2003: 228, 232; 2005: 989, fig. 2).

También se difundió por el resto de Occidente. La podemos ver enmarcando todos los recuadros del mosaico de las Musas de Tréveris (Parlasca, 1959: 32, láms. 32,4 y 33,2-4), en el mosaico dionisíaco de Colonia (Parlasca, 1959: 77, láms. 74,1 y 75,2) o en una de las orlas de un pavimento de la Domus Accanto al Serapeo, de Ostia (Becatti, 1961: láms. CCXII-CCXIII, n. ${ }^{\text { }} 283$ ), entre otros referentes formales (al respecto de lo que algunos especialistas franceses denominan «grecque fractionée», cfr. Balmelle et al., 2002: I, 74, lám. 32 e). Es un detalle ornamental frecuente en mosaicos norteafricanos, así, está presente en algunos de Sousse (Foucher, 1960: láms. XXXIII, 140, 143, XXXIV, 148-149, XLV, 203), en un ejemplar de la Casa de las Antigüedades, de Volubilis (LIMC, 2009: 236, lám. 1), etc.

Está emparentada con el marco interior de los cuadrados y losanges adyacentes del mosaico n. ${ }^{\circ} 1$ de la calle Armañá de Lugo (Torres, 2005: 482-483, fig. 5). Esta autora aduce que las grecas fraccionadas 
remarcando compartimentos responden a un gusto tardío, sirviéndonos ese dato de orientación a la hora de fechar este mosaico de Puente de la Olmilla. Es más, en la orla que delimita el contorno exterior de este mosaico se conjugan elementos ornamentales que se pueden poner en relación con los repertorios de época tardía. En definitiva, ciertos aspectos compositivos de este pavimento musivo son característicos de ejemplares tardíos, en especial de la segunda mitad del siglo IV d.C., lo que, unido a sus paralelismos, invita a considerar esa adscripción cronológica como la más adecuada para él, en consonancia con la documentación arqueológica. M.R. Puig Ochoa y R. Montanya Maluquer (1975: 143) ya propusieron esa datación, secundados por J.-G. Gorges (1979: 247) y J.M. Blázquez (1982c: 30).

\section{SÍNTESIS FINAL}

Recapitulando, el campo central de este mosaico de formato rectangular está dividido en tres paneles comprendidos en una amplia banda exterior integrada por rombos con peltas y motivos complementarios (tanto geométricos como esquematizaciones florales y vegetales). En los dos laterales, respectivamente encerrados en sendos rectángulos, se representan dos leopardos, uno de ellos plasmado en pleno salto o carrera -dirigiéndose hacia el centro- y el otro sentado, con la parte anterior de su cuerpo alzada. El modelado de las figuras se hace a base de una variada paleta cromática, con sutiles gradaciones de color, presentando una tendencia al claroscuro, efecto cromático que les hace destacar aún más sobre un fondo blanco. De gran calidad artística, su tratamiento estilístico les confiere un aspecto muy natural.

Aunque falta el casetón central (dañado desde antiguo), son notorios los rasgos comunes de esas figuras zoomorfas con las de numerosos mosaicos báquicos, por lo que es difícil sustraerse a la idea de su relación con ellos. Esta escena formada (originariamente) por una triple composición donde aparecen animales que usualmente son miembros del séquito de acompañamiento del dios Baco, vinculado a la difusión de la agricultura y el vino, parece hacer alusión a un tema idóneo para una villa rústica, más aún al estar estrechamente ligados los cultos dionisíacos a la fecundidad, una cuestión fundamental para toda explotación agropecuaria y, por ende, de interés prioritario para el dueño de ésta. Actividades propias de la finca, como la cosecha, la vendimia, etc., están asociadas a ese contexto. Este es, quizás, el espíritu que anima al cuadro e incluso podría entrañar un concepto bastante más complejo, implicando que el dominus estaba imbuido de unas determinadas creencias o ideas filosóficas (vid. supra). De ser así, este mosaico pudo haberle servido precisamente para exteriorizar sus convicciones o algunos de sus principios existenciales, posibilitándole la proyección a través de él de una presumible carga ideológica.

La ostentación tanto real como simbólica de unas corrientes religiosas y metafísicas vigentes entre muchos de los possessores hispanos del Bajo Imperio se exhibe en numerosos mosaicos del llamado «ciclo de los latifundia», es obvio, por tanto, que para ellos era importante dejarla patente, utilizando la musivaria como uno de los soportes y cauces de expresión más idóneos. Las escenas dionisíacas y cinegéticas se prodigan en los pavimentos de las villae de la Península, respondiendo la elección de las mismas no a una simple opción decorativa, sino al gusto de los latifundistas por los banquetes, la caza..., todo ello conectado con una espiritualidad pagana y una ideología propias de esa sociedad rural tardorromana, presumiblemente reivindicadas a través de ellos. Todo lo expuesto refuerza la idea del significado cultural de los mosaicos y nuestra percepción de que el extenso imaginario visual al que los musivarii recurren, con toda probabilidad, puede atribuirse a una deliberada intencionalidad de quienes los encargaron, traspasando el plano de lo meramente ornamental. En esa línea, algunos mosaicos habrían sido escogidos para demostrar la identificación de los comanditarios con los ideales y valores propugnados por el Estado romano (pilares tradicionales del sistema establecido).

Sea como fuere, el diseño figurativo de este mosaico subraya, sin duda, la importancia del recinto que decora, definiéndolo como uno de los más distinguidos de la villa. Atendiendo a que el thyasos se reproduce asiduamente en los programas pavimentales de los triclinia, dada la sagrada conexión entre Dionisos y el banquete, este criterio, pese a no ser concluyente, podría ayudarnos a definir el papel desempeñado por la unidad arquitectónica constituida por las habitaciones 1 y 2 , siendo esa la funcionalidad que nos parece más probable. No obstante, en caso de ser un espacio reservado, tal vez podría tratarse de uno de los llamados «dormitorios de aparato» (Novello, 2003: 144), ámbitos que suelen estar abiertos al peristilo y caracterizados por una monumentalidad considerable.

Para finalizar este intento de acercamiento a su significado, conviene señalar que con este mosaico se conseguiría fijar la atención del espectador desde su llegada a esta antecámara, tanto si se pretendía transmitirle consciente y tácitamente un mensaje (lo que parece factible), como si no. A pesar de contar con esta última posibilidad, pues no es seguro que podamos realizar una lectura más allá del simple aspecto estético o una temática de moda, adecuados a la sensibilidad artística del propietario, la primera opción, relativa a la semántica de las imágenes, en un manifiesto encriptado, resulta bastante verosímil a la hora de abordar el estudio de esta obra musiva.

\section{ANEXO}

A continuación transcribimos algunas noticias inéditas relativas a las primeras actuaciones arqueológicas llevadas a cabo en Puente de la Olmilla, que hemos recuperado indagando en el Archivo General de la Administración (fondo 109.2) y pueden resultar de 
interés para conocer mejor algunas circunstancias de la primera fase de intervención en este yacimiento (véase nota 1).

En una carta dirigida por el entonces alcalde de Albaladejo al Ministerio de Educación y Ciencia el 20-11-1973, comunica lo siguiente: «En el mes de agosto fueron descubiertos restos arqueológicos (...) y concretamente un mosaico en bastante buen estado de conservación. A raíz de ello visitaron nuestra población distintas personalidades (...). En vista de la llegada de los fríos, de nuevo se volvió a cubrir el mosaico descubierto, y los dueños de la finca donde se halla han arado el campo y seguramente se sembrará, lo que puede ocasionar la pérdida de este hallazgo. (...) se intente que no se cultive dicho campo, o por lo menos la zona señalada con posibles restos. Últimamente ha aparecido una columna que se ha roto (...)». Después, el alcalde solicita que se excave el yacimiento porque está expuesto a una probable destrucción, al continuar las labores agrícolas en ese paraje.

El 15 de febrero de 1974, el Director General de Bellas Artes emite una resolución al respecto: «Esta Dirección General ha resuelto que dos mosaístas del equipo de Mérida se desplacen a la citada localidad, a fin de proceder a su levantamiento y posterior traslado»».

En un nuevo escrito del alcalde, destinado al Comisario de Excavaciones Arqueológicas (J. Maluquer de Motes), con fecha 25-6-1974, se informa de que «En el presente mes de junio se han personado en esta población dos profesores de la Universidad de Barcelona que han procedido a descubrir el mosaico inicial [en referencia al sacado a la luz en agosto de 1973], habiendo aparecido otro en lo que se supone habitaciones contiguas de una posible casa de campo o recreo. (...) entendemos que no procede el que queden en el lugar donde se encuentran. (...) Téngase en cuenta que se hallan en pleno campo en fincas rústicas, y dada la maquinaria agrícola que se emplea, es muy posible que se destruya alguno, como efectivamente ocurrió en el primer mosaico hallado.» Finalmente, solicita que «(...) quede en nuestra población algún mosaico de los hallados».

La respuesta de J. Maluquer de Motes está fechada el 26-6-74: «he recibido esta misma mañana la orden de arrancar los dos mosaicos y trasladarlos a Ciudad Real»; seguidamente le manifiesta al alcalde que «el terreno está sembrado de garbanzos», pero no se pretende «causar perjuicio a los dueños».

A su vez, Daniel Lillo Castellanos, entonces alguacil del Ayuntamiento de Albaladejo, el 4-10-1974 escribe también al Comisario de Excavaciones Arqueológicas. Su carta contiene algunos datos esclarecedores. Comenta que el 26-8-1973 un grupo de aficionados locales participó, tras el hallazgo del primer mosaico, en los trabajos de limpieza de parte del mismo, comprobando «la poca capa de tierra que tenía el piso», localizado en una finca que lindaba con «un pedazo de garbanzos sembrados». Se infiere de ello que en las parcelas correlativas, por las que también se extiende el yacimiento, se realizaban, asimismo, labores agrícolas que acabarían afectando a los vestigios arqueológicos. Posteriormente se cultivaron de nuevo leguminosas, incluso en la parcela donde apareció el mosaico aquí estudiado, como se deduce de la misiva de J. Maluquer acabada de mencionar.

Tras finalizar el 20 de junio de 1974 la primera campaña de excavación, se procedió a la extracción de sendos mosaicos por parte de dos técnicos restauradores del equipo de Mérida pertenecientes a la Dirección General de Bellas Artes, siendo uno de ellos J. A. Díaz Pintiado ${ }^{7}$, que realizó los croquis correspondientes, hasta el momento actual inéditos (Figs. 14-15).

El 16-5-1974 figura este yacimiento en un expediente administrativo relativo a la provincia de Ciudad Real, con una partida presupuestaria «para las excavaciones de la villa romana de Albaladejo, interesante por sus mosaicos. Directores: D. José $\mathrm{M}^{\mathrm{a}}$ Álvarez Martínez, Técnico de esta Comisaría, $D^{a} M^{a}$ R. Puig, Profesora de la Universidad de Barcelona y D. Ramón Montañá. Fdo.: J. Maluquer de Motes, El Comisario General».

En otra carta dirigida a A. Blanco Freijeiro por R. Montanya («Encargado de curso de la Facultad de Letras de la UAB. Colaborador del Instituto de Arqueología y Prehistoria»), el 2-3-1977, le reitera: «Como Vd. sabe, es una típica villa tardo-imperial, de gran extensión (...); situada en una zona que hasta su descubrimiento ha permanecido intacta y desconocida arqueológicamente. (...) En la instancia enviada a comienzos de diciembre solicitando permiso de excavación para 1977, queríamos quedar incluidos en el plan de excavación de mi tío, el Dr. Maluquer de Motes; como quiera que al parecer este año mi tío no ha solicitado plan de excavaciones o al menos no nos ha incluido en el mismo, solicitamos (...) ser incluidos, o bien

7. J.A. Díaz Pintiado y su hija, Luisa Díaz, tuvieron la amabilidad de facilitarnos dos dibujos hasta ahora inéditos, que obraban en poder del primero, con el boceto del esquema compositivo de los mosaicos de las habitaciones n..$^{\circ} 1$ y 2 (Figs. 14-15), además de brindarnos algunos datos sobre su extracción, que reproducimos seguidamente.

La fecha de arranque fue el 28 de junio de 1974 y la de consolidación el 4 de julio del mismo año.

Las dimensiones que nos ha proporcionado J. A. Díaz del mosaico de la habitación $n .^{\circ} 1$ son $4,65 \times 7,40 \mathrm{~m}$ (hay una mínima diferencia, de $5 \mathrm{~cm}$, respecto a las medidas dadas por Puig y Montanya, 1975, 134). Fue dividido en 23 placas para su extracción. Faltaba gran cantidad del teselado en las placas n. ${ }^{\circ} 16,17,18,20,21,22$ y 23.

En cuanto al mosaico de la habitación $n^{\circ}$ 2, tiene adosado un lienzo subdividido en dos paños. Según sus apuntes, el conjunto mide 3,60 x 4,65 m (también aquí se aprecia una diferencia de $5 \mathrm{~cm}$ ). Fue dividido en 12 placas. A la n. 5 (correspondiente al panel central) le faltaba el teselado casi por completo.

La consolidación se realizó con argamasa de cemento gris Portland y arena, en proporción 1:3 partes, con agua. En el interior del fraguado se introdujo una malla metálica para dar mayor resistencia, según información suministrada por él mismo y por Luisa Díaz, a quienes queremos expresar nuestro más sincero agradecimiento por dicha aportación al estudio que hemos llevado a cabo sobre este mosaico. 


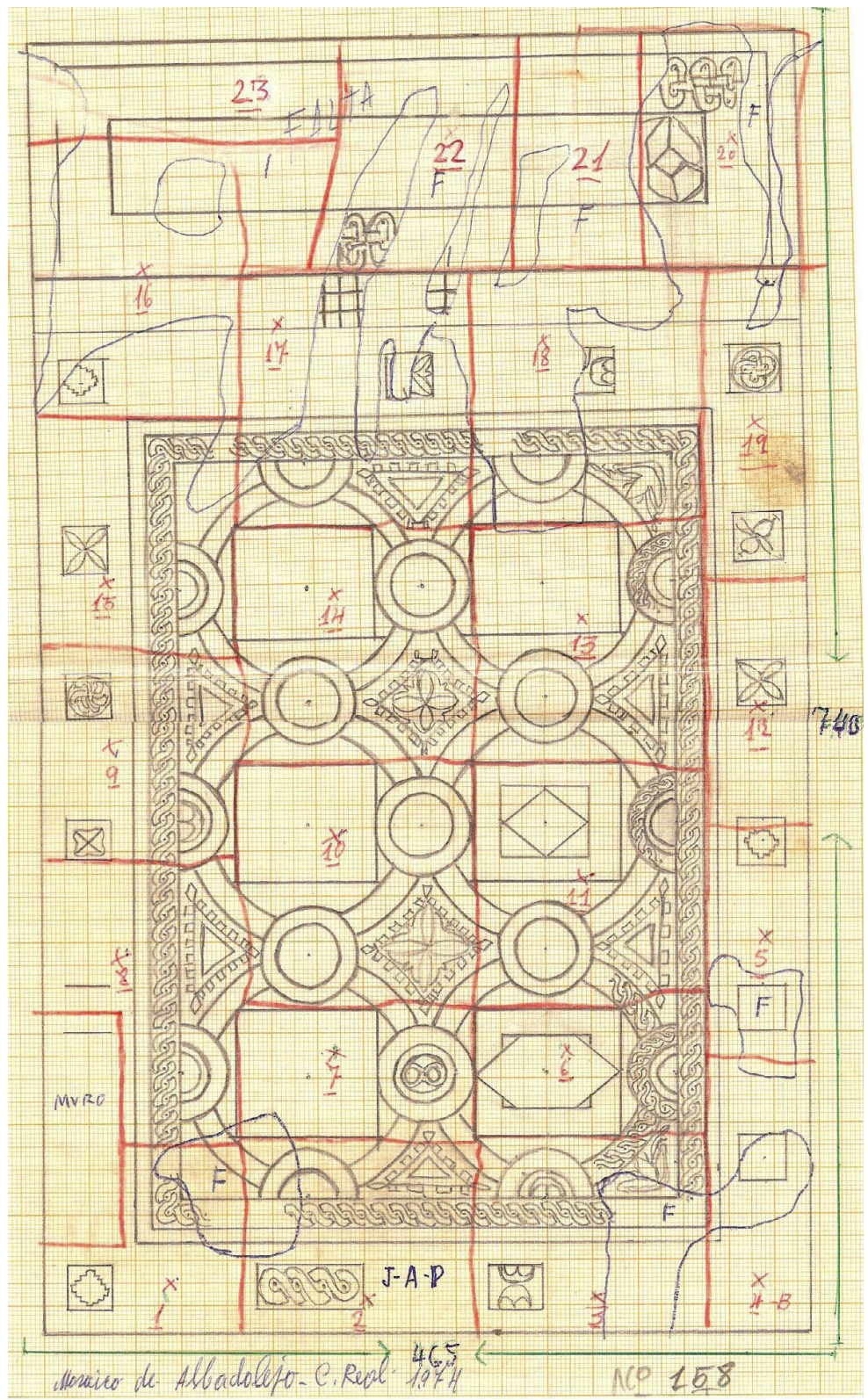

Figura 14: Dibujo del mosaico de la habitación n. ${ }^{\circ}$ 1. Dib.: Díaz Pintiado.

en el plan de excavaciones del Dr. Palol (...), o si es posible (...) nos sea concedido permiso y subvención como miembros colaboradores del Instituto (...)»).

El 19-4-1977 fue concedido dicho permiso por el Ministerio de Cultura, «bajo la dirección de $\mathrm{M}^{\mathrm{a}} \mathrm{R}$. Puig». Por lo tanto, desde su descubrimiento a finales de 1973, la villa fue objeto de varias campañas de intervención arqueológica. En 1979 no se excavó, a pesar de haberse solicitado renovación del permiso para acometer entonces una sexta campaña, siendo ésta aplazada hasta 1980. Tras esa campaña se interrumpió la intervención, pese a que el 27 de diciembre de ese año $\mathrm{M}^{\mathrm{a}}$. R. Puig solicitó el permiso correspondiente a 1981. El 6-2-1981 le comunican desde la Subdirección General de arqueología que debido a las transferencias en materia de arqueología a la Generalidad de Cataluña, con efecto desde el 1 de enero, no se podía cursar una nueva intervención dentro del Plan del Instituto de Prehistoria y Arqueología de la Universidad de Barcelona, recordándole también «que el número de campañas realizadas en Albaladejo excede el plazo que, en la normativa actual, se considera para la presentación de una Memoria a publicar en nuestras series oficiales. Es por ello que (...) se hace necesario recibamos esa Memoria antes de proseguir (...) las excavaciones». En un nuevo escrito dirigido por $\mathrm{M}^{\mathrm{a}}$. R. Puig a la Subdirección General de arqueología, con fecha 5-3-1981, dice estar de acuerdo «en que la excavación en Albaladejo pase a integrarse en el Plan de excavaciones del Museo Provincial de Ciudad Real». Le responden el 4-5-1981, autorizando una nueva campaña para el año en curso. Pese a ello, no hemos encontrado ninguna documentación que explique por qué no tuvo lugar, pues entre las inversiones en excavaciones 


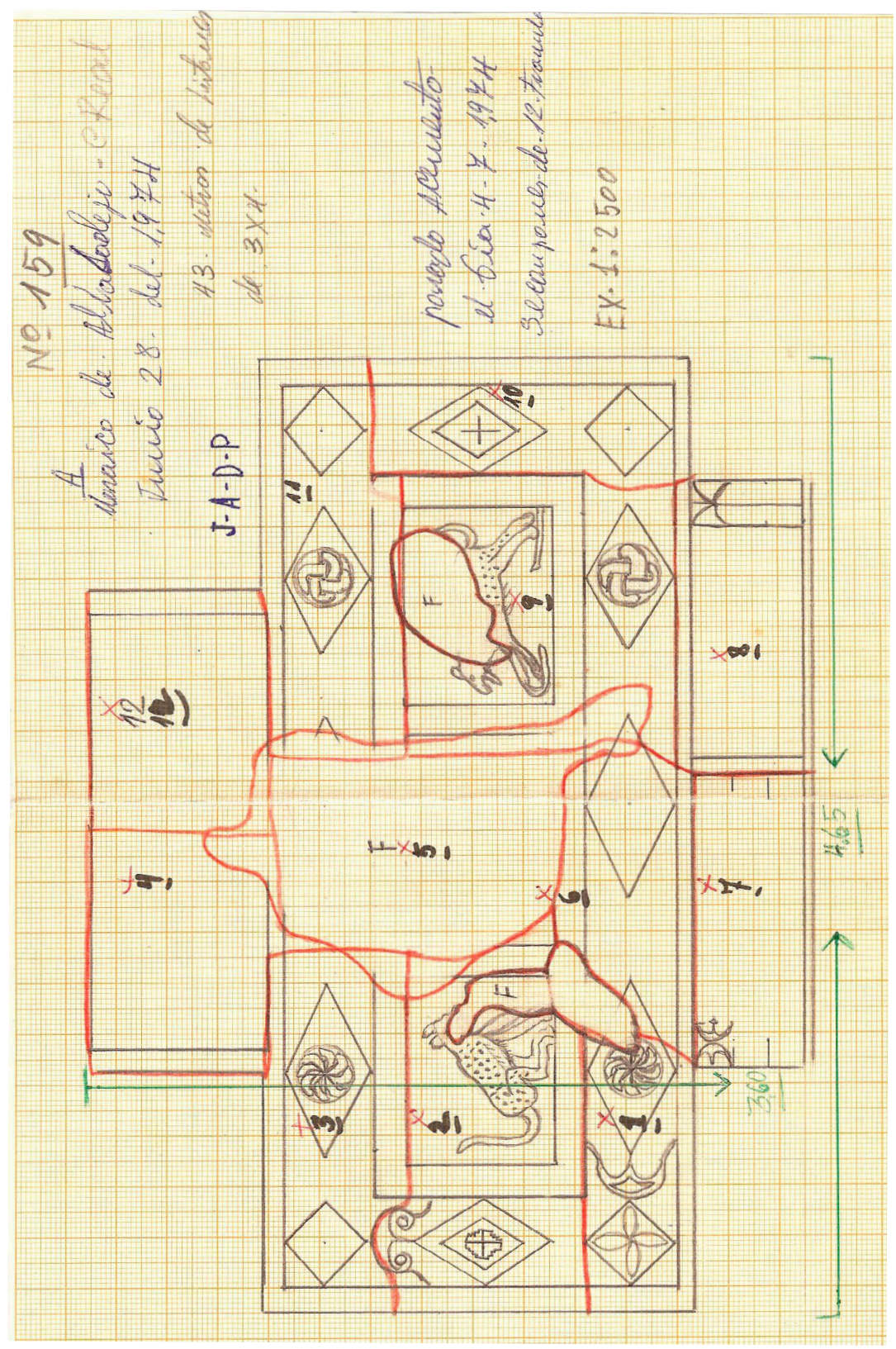

Figura 15: Dibujo del mosaico de la habitación n. ${ }^{\circ}$ 2. Dib.: Díaz Pintiado.

arqueológicas programadas por la Dirección General de Bellas Artes, Archivos y Bibliotecas del Ministerio de Cultura estaba concedida una partida presupuestaria para 1981, como consta en varios expedientes de dicho organismo, uno de ellos de fecha 8-6-1981, con la relación de todas ellas aprobada por la Junta Superior de Excavaciones y Exploraciones Arqueológicas.

Mención aparte merece la carta dirigida por $\mathrm{M}^{\mathrm{a}}$. Dolores Fernández-Posse a $\mathrm{M}^{\mathrm{a}}$. R. Puig en los siguientes términos: «Esta Subdirección ha determinado incluir la villa de Albaladejo en las declaraciones, para el año 1980, de MONUMENTO HISTÓRICO-ARTÍSTICO Y ARQUEOLÓGICO (...) en vistas a su conservación y protección». Le pide después que presente un informe sucinto «y un plano o croquis de la zona del yacimiento donde determine cuál es el perímetro que estará sujeto a la declaración». Sin embargo, no tenemos constancia de que se aportara dicha documentación $\mathrm{y}$, desafortunadamente, tal declaración no se llevó a cabo, por causas hasta el momento desconocidas.

Reproducimos también diversa información del archivo del Museo Provincial de Ciudad Real:

El 19-6-1980 Mª. R. Puig escribió a R. García Serrano, entonces Director de dicho Museo: «Con respecto a los mosaicos de Albaladejo, se nos ha comunicado por parte del Ministerio de Cultura que se va a declarar el yacimiento Monumento Histórico-Artístico y Arqueológico. Ello cambia nuestra idea inicial sobre el traslado de estos mosaicos a C. Real, ya que lógicamente deberán conservarse 'in situ'. (...) es necesario que hablemos del futuro de esta excavación».

Evidentemente, los acontecimientos siguieron otro curso y el 5-6-1981 los dos mosaicos descubiertos en 1973 fueron trasladados al Museo de Ciudad Real, 
donde quedaron depositados. Con fecha 16-6-1981, el alcalde de Albaladejo, Andrés García Arce, dirige una carta a la Subdirección General de Arqueología y Etnología solicitando traslado de alguno de esos mosaicos a su localidad. El 2-9-1981 reciben respuesta de dicho organismo accediendo a su petición si «se procediera a una instalación adecuada que permitiera la visita de los restos arqueológicos y garantizar la seguridad de su conservación» (fondo 109.2). A raíz de ello, se instaló el pavimento de la habitación n. ${ }^{\circ} 1$ (Figs. 2 y 12) en una de las paredes de la Casa de Cultura de Albaladejo.

En cambio, al no haberse procedido a la consolidación y restauración de las ruinas exhumadas, ni haberse levantado las placas de estuco (para ser más exactos, sólo algún fragmento de ellas), se perdieron lamentablemente la mayoría de las pinturas descubiertas, dada su extrema fragilidad. No en vano, en un expediente administrativo de la Delegación Provincial de Cultura, en Ciudad Real, fechado en 1983, «se da a conocer el abandono en que se encuentra» la villa. Tras acordarse una visita de Alfonso Caballero Klink, el entonces Director del Museo Provincial de Ciudad Real emitió un informe relativo a su penosa situación. En otro documento conservado en el archivo de dicho Museo figura una relación de los yacimientos de esta provincia «en los que se realizaron varias campañas de excavación pero que, sin razón aparente que lo justifique, no se continuaron los trabajos: PUENTE DE LA OLMILLA. Albaladejo. Villa romana. Se realizaron excavaciones hasta 1980. Interrumpidas éstas, no se ha vuelto a renovar el Permiso ni (...) se ha presentado la preceptiva Memoria de excavaciones. Dirección de los trabajos: M. Rosa Puig».

\section{REFERENCIAS}

Alföldy, G. (2012). Nueva historia social de Roma. Sevilla: Universidad de Sevilla.

Angiolillo, S. (1981). Mosaici antichi in Italia. Sardinia. Roma: E. C. Portale.

Aurigemma, S. (1960). L'Italia in Africa. Le scoperte archeologiche (a. 1911-1943). Tripolitania I. Parte prima: Imosaici. Roma: Ministero degli Affari Esteri.

Balil Illana, A. (1965). Algunos mosaicos hispanorromanos de época tardía. Príncipe de Viana, 100-101, 281-292.

Balil Illana, A. (1979). Estudios sobre mosaicos romanos, V, Studia Archaeologica, 49. Valladolid: Universidad de Valladolid.

Balil Illana, A. (1986). El oficio del musivario. Boletín del Seminario de Estudios de Arte y Arqueología de la Universidad de Valladolid, LII, 143-161.

Balmelle, C. et al. (1985-2002). Le décor géométrique de la mosaïque romaine. París: Picard.

Balmelle, C. et al. (1999). Nouveaux apports à la connaissance de la mosaïque gallo-romaine. En M. Ennaïfer y A. Rebourg (Eds.). Actes du Colloque. La Mosaïque Gréco-romaine, VII,
2 (Tunis, 1994) (pp. 627-637). Tunis: Institut National du Patrimoine.

Balmelle, C. y Darmon, J. P. (1986). L'artisan-mosaïste dans l'Antiquité Tardive. Réflexions à partir des signatures. En X. Barral i Altet (Ed.). Actes du Colloque international. Artistes, artisans et production artistique au Moyen Age, I (Rennes, 1983) (pp. 235-253). París: Centre National de la Recherche Scientifique.

Becatti, G. (1961). Scavi di Ostia IV. Mosaici e pavimenti marmorei. Roma: Libreria dello Stato.

Bendala Galán, M. y Abad Casal, L. (2008). La villa en el marco conceptual e ideológico de la ciudad tardorromana. En C. Fernández Ochoa, V. García-Entero y F. Gil Sendino (Eds.). Las villae tardorromanas en el Occidente del Imperio: arquitectura y función. IV Coloquio Internacional de Arqueología en Gijón (pp. 17-25). Gijón: Ediciones Trea.

Bianchi-Bandinelli, R. (1971). Roma. El Fin del Arte Antiguo. Madrid: Aguilar.

Blake, M.E. (1930). The Pavements of the Roman Buildings of the Republic and Early Empire. Memoirs of the American Academy in Rome, VIII, 7-160.

Blanchard-Lemée, M. (2005). Le triclinium à la mosaïque dionysiaque de Sétif (Algérie). En H. Morlier (Dir.). Actes $d u$ Colloque. La Mosaïque Gréco-romaine, IX, 1 (Roma, 2001) (pp. 291-301). Collection de l'École française de Rome, 352. Roma: École française de Rome.

Blanco Freijeiro, A. (1952). Mosaicos antiguos de asunto báquico. Madrid: Maestre.

Blanco Freijeiro, A. (1978a). Mosaicos romanos de Itálica, Corpus de Mosaicos Romanos de España, II (1). Madrid: Consejo Superior de Investigaciones Científicas.

Blanco Freijeiro, A. (1978b). Mosaicos romanos de Mérida, Corpus de Mosaicos Romanos de España, I. Madrid: Consejo Superior de Investigaciones Científicas.

Blázquez Martínez, J. M. (1981). Mosaicos romanos de Córdoba, Jaén y Málaga, Corpus de Mosaicos Romanos de España, III. Madrid: Consejo Superior de Investigaciones Científicas.

Blázquez Martínez, J. M. (1982a). Mosaicos romanos de Sevilla, Granada, Cádiz y Murcia. Corpus de Mosaicos Romanos de España, IV. Madrid: Consejo Superior de Investigaciones Científicas.

Blázquez Martínez, J. M. (1982b). Historia de España. España Romana (Menéndez Pidal), II/1-2. Madrid: Espasa Calpe

Blázquez Martínez, J. M. (1982c). Mosaicos romanos de la Real Academia de la Historia, Ciudad Real, Toledo, Madrid y Cuenca. Corpus de Mosaicos Romanos de España, V. Madrid: Consejo Superior de Investigaciones Científicas.

Blázquez Martínez, J. M. (1984). Mosaicos báquicos en la Península Ibérica. Archivo Español de Arqueología, 57, 69-96.

Blázquez Martínez, J. M. (1986). Mosaicos hispanos de la época de las invasiones bárbaras. Problemas estéticos. Antigüedad y Cristianismo, III, 463-489. 
Blázquez Martínez, J. M. (1987a). Transformaciones sociales. Descomposición de las formas artísticas en la Antigüedad Clásica. Fragmentos, 10, 25-37.

Blázquez Martínez, J. M. (1987b). Arte y mitología en los mosaicos palentinos. En Diputación Provincial de Palencia (Ed.). Actas del I Congreso de Historia de Palencia I (Palencia, 1985) (pp. 361-408). Palencia: Diputación Provincial de Palencia.

Blázquez Martínez, J. M. (1990). Aportaciones al estudio de la España Romana en el Bajo Imperio. Madrid: Istmo.

Blázquez Martínez, J. M. (1993). Mosaicos Romanos de España. Madrid: Cátedra.

Blázquez Martínez, J.M. (1994). El entorno de las villas en los mosaicos de África e Hispania. En A. Mastino y P. Ruggeri (Eds.). Atti del X Convegno di Studi su l'Africa Romana (Oristano, 1992) (pp. 1171-1187). Sassari: Archivio fotografico Sardo.

Blázquez Martínez, J. M. (2008). Mosaicos romanos en Castilla-La Mancha (provincias de Ciudad Real, Toledo, Albacete, Cuenca y Guadalajara). En G. Carrasco Serrano (Coord.). La romanización en el territorio de Castilla-La Mancha. Simposium en la colección de estudios, 120 (pp. 91-125). Cuenca: Universidad de Castilla-La Mancha.

Blázquez Martínez, J. M. y González Navarrete, J. (1972-74). Mosaicos hispánicos del Bajo Imperio. Archivo Español de Arqueología, 45-47, 419-438.

Blázquez Martínez, J. M., López Monteagudo, G., Mañanes, T. y Fernández Ochoa, C. (1993). Mosaicos romanos de León y Asturias. Corpus de Mosaicos Romanos de España, X. Madrid: Consejo Superior de Investigaciones Científicas.

Blázquez Martínez, López Monteagudo, G., Neira, M. L. y San Nicolás, M. P. (1986). La mitología en los mosaicos hispano-romanos. Archivo Español de Arqueología, 59, 101-162.

Blázquez Martínez, López Monteagudo, G., Neira, M. L. y San Nicolás, M. P. (1989). Mosaicos romanos del Museo Arqueológico Nacional. Corpus de Mosaicos Romanos de España, IX. Madrid: Consejo Superior de Investigaciones Científicas.

Blázquez Martínez, J. M. y Mezquíriz Irujo, M. A. (1985). Mosaicos romanos de Navarra. Corpus de Mosaicos Romanos de España, VII. Madrid: Consejo Superior de Investigaciones Científicas.

Blázquez Martínez, J. M. y Ortego, T. (1983). Mosaicos Romanos de Soria. Corpus de Mosaicos Romanos de España, VI. Madrid: Consejo Superior de Investigaciones Científicas.

Bruneau, P. (1972). Exploration Archéologique de Délos, XXIX. Les Mosaïques. París: École Française d'Athènes.

Bruneau, P. (1984). Les mosaïstes antiques avaient-ils des cahiers de modèles?. Revue Archéologique, 2, 241-272.

Campbell, S. (1994). Good luck symbols on Spanish mosaics. En C. M. Batalla (Ed.). Actas del VI Coloquio Internacional sobre Mosaico Antiguo (Palencia-Mérida, 1990) (pp. 293300). Palencia: Junta de Castilla y León.
Carandini, A. (1962). Ricerche sui problema dell'ultima pittura tardo-antica nel bacino del Mediterraneo Meridionale. Archeologia Classica, 14, 217-235.

Carandini, A. et al. (1982). Filosofiana: La Villa de Piazza Armerina. Immagine di un aristocratico romano al tempo di Constantino. Palermo: S. F. Flaccovio.

Chavarría Arnau, A. (2006). Villas en Hispania durante la Antigüedad Tardía. En A. Chavarría, J. Arce y G. P. Brogiolo (Eds.). Villas Tardoantiguas en el Mediterráneo Occidental. Anejos de Archivo Español de Arqueología, XXXIX (pp. 1735). Madrid: Consejo Superior de Investigaciones Científicas.

Chavarría Arnau, A. (2007). El final de las villae en Hispania (siglos IV-VII d.C. Bibliothèque de l'Antiquité tardive, 7. Thurhout (Bélgica): Brepols.

Cimok, F. (2000). Antioch Mosaics. A Corpus. Estambul: A Turizm Yayinlari Ltd.

Dorigo, W. (1966). Pittura tardoromana. Milán: Feltrinelli.

Dunbabin, K.M.D. (1971). The Triumph of Dionysus on Mosaics in North Africa. En R. Ling (Ed.). Papers of the Brithish School of Rome, XXXIX (pp. 52-65). Roma: Brithish School of Rome.

Dunbabin, K.M.D. (1978). The Mosaics of Roman North Africa. Studies in Iconography and Patronage. Oxford: Clarendon Press.

Dunbabin, K.M.D. (1999). Mosaics of the greek and roman world. Cambridge: Cambridge University Press.

Dunbabin, K.M.D. (2003). The Roman banquet. Images of Conviviality. Cambridge: Cambridge University Press.

Durán Penedo, M. (2010). Temas iconográficos relacionados con la producción de la tríada mediterránea en los mosaicos del Norte de África y de Hispania, su interrelación con la Annona. En M. Milanese, P. Ruggeri y C. Vismara (Eds.). Atti del XVIII Convegno Internazionale di Studi su l'Africa Romana (Olbia, 2008) (pp. 501-526). Roma: Carocci editore.

Farioli Campanati, R. (1971). Ambientazione e idee informatrice del mosaico pavimentale Ravennate, con particolare riferimento ai mosaici rinvenuti a Classe. XVIII Corso di Culture sull'Arte Ravennate e Bizantina. Ravenna: Longo.

Farioli Campanati, R. (1975). Pavimenti musivi di Ravenna Paleocristiana. Ravenna: Longo.

Fernández Castro, M. C. (1982). Las villas romanas en España. Madrid: Ministerio de Cultura.

Fernández Castro, M. C. (1983). Mosaicos de la villa de Cuevas de Soria. En J. M. Blázquez y T. Ortego. Mosaicos romanos de Soria. Corpus de Mosaicos Romanos de España, VI (pp. 59-106). Madrid: Consejo Superior de Investigaciones Científicas.

Fernández-Galiano Ruiz, D. (1975). Un valioso mosaico hallado en Alcalá de Henares. Actas del XIII Congreso Nacional de Arqueología (Huelva, 1973) (pp. 921-928). Zaragoza: Universidad de Zaragoza.

Fernández-Galiano Ruiz, D. (1984a). Complutum, II. Mosaicos. Excavaciones Arqueológicas en España, 138. Madrid: Ministerio de Cultura. 
Fernández-Galiano Ruiz, D. (1984b). El triunfo de Dionisos en mosaicos hispanorromanos. Archivo Español de Arqueología, 57, 97-121.

Fernández Ochoa, C. y Baena del Alcázar, L. (1992). Esculturas romanas de la provincia de Ciudad Real. En F. Acuña Castroviejo (Coord.). Finis Terrae, Estudios en lembranza do Prof. Dr. Alberto Balil (pp. 333-345). Santiago de Compostela: Universidade de Santiago de Compostela.

Foucher, L. (1960). Inventaire des mosaïques, Feuille $n .^{\circ} 57$ de l'Atlas Archéologique de Sousse, Túnez (= Inv. Sousse). Tunis: Institut National d'archéologie et arts.

Foucher, L. (1961). Découvertes archéologiques à Thysdrus en 1960, Notes et Documents, IV. Tunis: Impr. de la Rapide.

Foucher, L. (1964). Hadrumetum. París: Presses Universitaires de France.

Foucher, L. (1975). Le char de Dionysos. En H. Stern y M. Le Glay (Ed.). Actes du Colloque. La Mosaïque Gréco-romaine, II (Vienne, 1971) (pp. 55-61). París: Centre National de la Recherche Scientifique.

García y Bellido, A. (1960). Colonia Aelia Augusta Italica. Madrid: Instituto español de arqueología.

García y Bellido, A., 1965. Los mosaicos romanos de la Plaza de la Corredera en Córdoba. Boletín de la Real Academia de la Historia, CLVII, 183-196.

García Bueno (1994). Mosaicos de la villa romana de Puente de la Olmilla (Albaladejo, C. Real). Veleia, 11, 95-116.

García Bueno, C. (2000). Problemática de la arqueología romana en la provincia de Ciudad Real: la villa de Puente de la Olmilla (Albaladejo). En L. Benítez de Lugo (Coord.). El patrimonio arqueológico de Ciudad Real. Métodos de trabajo y actuaciones recientes (pp. 191-203). Valdepeñas (Ciudad Real): Centro Asociado de la Universidad Nacional de Educación a Distancia.

García Bueno, C. (2001). Apuntes para el estudio de los mosaicos de la villa romana de Puente de la Olmilla (Albaladejo, Ciudad Real). Pátina, 10 y 11, 212-217.

García Bueno, C. (2011). Uso y disfrute del agua en la villa romana de Puente de La Olmilla (Albaladejo, Ciudad Real). El aprovechamiento hídrico en el Mundo Romano. Espacio, Tiempo y Forma, Serie II, 24, 449-472. DOI: http://dx.doi. org/10.5944/etfii.24.2011.1877

García Bueno, C. (2014). La romanización de Ciudad Real. Poblamiento rural romano en el Suroeste del conventus Carthaginiensis durante el Bajo Imperio: las villae del barrio de Sta. María de Alcázar de San Juan y Puente de la Olmilla, Albaladejo (Ciudad Real). (Tesis doctoral inédita). Universidad Complutense de Madrid. Madrid.

García Bueno, C. (2015a). Aspectos constructivos y decorativos de la villa romana de Puente de la Olmilla (Albaladejo, Ciudad Real). Lucentum, XXXIV, 207-230. DOI: http:// dx.doi.org/10.14198/LVCENTVM2015.34.08

García Bueno, C. (2015b). Hallazgos monetarios del yacimiento romano de Puente de la Olmilla (Albaladejo, Ciudad Real). Numisma, 259, 145-172.

García Bueno, C. (2015c). Interpretación funcional de los espacios domésticos de la villa romana de Puente de la Olmilla
(Albaladejo, Ciudad Real). Herakleion, 8, 119-162. Recuperado de: http://www.herakleion.es_

García Bueno, C. (2016). Un nuevo mosaico de los Cuatro Vientos, en la villa hispanorromana de Puente de la Olmilla (Albaladejo, Ciudad Real). En L. Neira Jiménez (Ed.). Actas del XIII Congreso de l'Association internationale pour l'étude de la mosaïque antique. (Madrid, 2015) (pp. 352357). Roma: L'ERMA.

García Bueno, C. (e. p.). Algunas observaciones sobre los pavimentos musivos de la villa romana de Puente de la Olmilla (Albaladejo, Ciudad Real). El mosaico de la habitación absidiada. Romula, 15.

García Guinea, M. A. (1977). Los mosaicos tardorromanos de Quintanilla de la Cueza (Palencia). En Universitat de Barcelona, Instituto de Arqueología y Prehistoria (Ed.). Segovia y la Arqueología romana. Symposium de Arqueología Romana Bimilenario de Segovia (Segovia, 1977) (pp. 187-191). Barcelona: Universidad de Barcelona.

García Sanz, O. (1990): Baco en Hispania. Economía y Religión, a través de las fuentes epigráficas, arqueológicas y literarias. (Tesis doctoral). Colección Tesis Doctorales. Madrid: Universidad Complutense de Madrid.

García Sanz, O. (1991-1992). Algunos apuntes sobre Baco en Hispania. Anas, 4-5, 105-114.

García Sanz, O. (1994). El Baco hispano a través de sus mosaicos. En C. M. Batalla (Ed.). Actas del VI Coloquio Internacional sobre Mosaico Antiguo (Palencia-Mérida, 1990) (pp. 327-332). Palencia: Junta de Castilla y León.

Germain, S. (1969). Les Mosaïques de Timgad. Études descriptive et analytique. París: Centre National de la Recherche Scientifique.

González Cordero, A. et al. (1990). Mosaicos de la villa romana de «Torre Albarragena»: un nuevo triunfo báquico en la Península Ibérica. Archivo Español de Arqueología, 63, 317-330.

Gorges, J.-G. (1979). Les villas hispano-romaines. Inventaire et problématique archéologiques. París: E. de Boccard.

Guardia Pons, M. (1992). Los mosaicos de la Antigüedad tardía en Hispania. Estudios de iconografía. Barcelona: Promociones Publicaciones Universitarias

Hinks, R. P. (1933). Catalogue of the Greek, Etruscan and Roman paintings and mosaics in the British Museum. Londres: British Museum.

Hurtado Aguña, J. (2005). Los territorios septentrionales del Conventus Carthaginensis durante el Imperio romano. Estudio de la romanización de Carpetania. Oxford: British Archaeological Reports. John \& Erica Hedges Ltd.

Lancha, J. (1994). Les mosaïstes dans la partie occidentale de l'Empire romain. Cuadernos Emeritenses, 8, 119-136.

Lavagne, H. (1979). Recueil général des mosaïques de la Gaule III. Province Narbonnaise 1. Partie centrale, X supplèment à «Gallia». París: Centre National de la Recherche Scientifique.

Levi, D. (1947). Antioch Mosaic Pavements, Iy II. Princeton: Princeton University Press. 
LIMC. (2009). Lexicon iconographicum mythologiae classicae, Supp. 1-2. Düsseldorf: Artemis Verlag.

López Monteagudo, G. (1990). El programa iconográfico de la Casa de los Surtidores en Conimbriga. Espacio, Tiempo y Forma, Serie II, 3, 199-232.

López Monteagudo, G. (1997). Personificaciones alegóricas en mosaicos del Oriente y de Hispania: la representación de conceptos abstractos. Antigüedad y Cristianismo, XIV, 335-361.

López Monteagudo, G. (1999). The Triumph of Dionysus in two Mosaics in Spain. Assaph, 6, 35-60.

López Monteagudo, G. (2002). Mosaicos romanos y élites locales en el N. de África y en Hispania. Archivo Español de Arqueología, 75, 251-268. DOI: http://dx.doi.org/10.3989/ aespa.2002.v75.138

López Monteagudo, G. (2004). Mosaicos romanos del Norte de África: la «no frontera» entre la tierra y el mar. En M. Khanoussi, P. Ruggeri y C. Vismara (Eds.). Atti del XV Convegno di Studi su l'Africa Romana (Tozeur, 2002) (pp. 305-326). Roma: Carocci editore.

López Monteagudo, G. (2012). Paisajes productivos del agro en los mosaicos romanos del Norte de África. En M. Bastiana Cocco, A. Gavini y A. Ibba (Eds.). Atti del XIX Convegno di Studi su l'Africa Romana (Sassari, 2010) (pp. 669-690). Roma: Carocci editore.

López Monteagudo, G. et al. (1999). Recientes hallazgos de mosaicos romanos figurados en Hispania. En M. Ennaïfer y A. Rebourg (Eds.). Actes du Colloque. La Mosaïque Grécoromaine, VII, 2 (Tunis, 1994) (pp. 509-542). Tunis: Institut National du Patrimoine.

López Monteagudo, G. y Blázquez Martínez, J. M. (1990). Destrucción de mosaicos mitológicos por los cristianos. Antigüedad y Cristianismo, VII, 353-365.

López Monteagudo, G., Navarro Sáez, R. y Palol Salellas, P. de (1998). Mosaicos romanos de Burgos. Corpus de Mosaicos Romanos de España, XII. Madrid: Consejo Superior de Investigaciones Científicas.

Loring García, M. I. (1986-1987). La difusión del cristianismo en los medios rurales de la Península Ibérica a fines del Imperio Romano. Studia Historica. Historia Antigua, IV$V(1), 195-204$.

Mañas Romero, I. (2007-2008). El pavimento musivo como elemento en la construcción del espacio doméstico. Anales de Prehistoria y Arqueología, 23-24, 89-117.

Mañas Romero, I. (2011). Dos mosaicos báquicos en casas de Itálica. En Actes du Colloque. La Mosaïque Gréco-romaine, $X$ (Conimbriga, 2005) (pp. 367-380). Coimbra: Comissâo Executiva do $\mathrm{X}^{\mathrm{o}}$ Colloque de l'Association internationale pour l'étude de la mosaïque antique.

Mezquíriz Irujo, M. A. (2003). La villa romana de Arellano. Pamplona: Institución Príncipe de Viana.

Mezquíriz Irujo, M. A. et al. (1993-1994). La villa de las Musas (Arellano-Navarra). Estudio previo. Trabajos de Arqueología Navarra, 11, 55-100.

Mezquíriz Irujo, M. A. y Unzu Urmeneta, M. (2005). Los mosaicos de la villa romana de Arellano (Navarra-España).
En H. Morlier (Dir.). Actes du Colloque. La Mosaïque Grécoromaine, IX, 2 (Roma, 2001) (pp. 987-999). Collection de l'École française de Rome, 352. Roma: École française de Rome.

Moreno González, M. F. (1995). Aspectos técnicos, económicos, funcionales e ideológicos del mosaico romano. Una reflexión. Anales de Arqueología Cordobesa, 6, 113-143.

Neira Jiménez, M. L. (2007). Aproximación a la ideología de las elites en Hispania durante la Antigüedad Tardía. A propósito de los mosaicos figurados de domus y villae. Anales de Arqueología Cordobesa, 18, 263-290.

Neira Jiménez, M. L. (2008). Las villae: ¿espacio de representación?. El testimonio de los mosaicos. En V. Revilla Calvo, J.-R. González Pérez y M. Prevosti Monclús (Eds.). Actes del Simposi: Les vil.les romanes a la Tarraconense I (Lérida, 2007) (pp. 55-80). Barcelona: Biblioteca de Catalunya.

Neira Jiménez, M. L. (2009). La imagen en los mosaicos romanos como fuente documental acerca de las elites en el Imperio Romano. Claves para su interpretación. Estudos da Lingua(gem). Imagens e Memoria, 7(1), 11-53.

Neira Jiménez, M. L. (2010). Oficios relacionados con el mosaico en las provincias romanas del Norte de África. En M. Milanese, P. Ruggeri y C. Vismara (Eds.). Atti del XVIII Convegno di Studi su l'Africa Romana (Olbia, 2008) (pp. 483498). Roma: Carocci editore.

Neira Jiménez, M. L. (2011). Reflejo de cambios sociales en algunas representaciones de mosaicos romanos de la pars occidentalis. En: Actes du Colloque. La Mosaïque Grécoromaine, X (Conimbriga, 2005) (pp. 267-282). Coimbra: Comissâo Executiva do $\mathrm{X}^{\mathrm{o}}$ Colloque de l'Association internationale pour l'étude de la mosaïque antique.

Novello, M. (2003). Il ruolo dell apparato decorativo nella caratterizzacione funzionale dello spazio abitativo. En S. Bullo y F. Ghedini (Eds.). Amplissimae atque ornatissimae domus (Aug., civ., II, 20,26): l'edilizia residenziale nella città della Tunisia romana (pp. 356-360). Padua: Edizioni Quasar.

Ortego y Frías, T. (1965). La villa romana de Santervás del Burgo (Soria). Archivo Español de Arqueología,

$38,86-91$

Ovadiah, A., Gómez de Silva, C. y Mucznik, S. (1991). The Mosaic Pavements of Sheikh Zouède in Northern Sinai. Jahrbuch für Antike und Christentum (Tesserae - Festschrift J. Engemann), 18, 181-191.

Palol Salellas, P. de (1967). Arqueología cristiana de la España romana. Valladolid-Madrid: Consejo Superior de Investigaciones Científicas.

Palol Salellas, P. de (1977-78). La cristianización de la aristocracia romana hispánica. Pyrenae, XIII-XIV, 281-300.

Palol Salellas, P. de y Cortes Álvarez de Miranda, J. de (1974). La villa romana de la Olmeda, Pedrosa de la Vega (Palencia). Excavaciones de 1969-1970. Acta Arqueológica Hispánica 7, I. Madrid: Ministerio de Educación y Ciencia. Dirección General del Patrimonio Artístico y Cultural.

Parlasca, K. (1959). Die römische Mosaiken in Deutschland. Berlín: Walter de Gruyter. 
Puig Ochoa, M. R. y Montanya Maluquer, R. (1975). Mosaicos de la villa romana de Puente de la Olmilla (Albaladejo, Ciudad Real). Pyrenae, XI, 133-143.

Puig Ochoa, M. R. y Montanya Maluquer, R. (1977). Informe arqueológico de la campaña de 1977. (Informe inédito depositado en el Archivo General de la Administración). Alcalá de Henares.

Ramallo Asensio, S. (1990). Talleres y escuelas musivas en la Península Ibérica. En C. M. Batalla Carchenilla (Ed.). Actas del Homenaje in Memoriam de A. Balil Illana (Guadalajara, 1990) (pp. 135-180). Guadalajara: Ministerio de Cultura.

Regueras Grande, F. (1991). Algunas consideraciones sobre los mosaicos de la provincia de Zamora. Boletín del Seminario de Estudios de Arte y Arqueología de la Universidad de Valladolid, 57, 163-177.

Regueras Grande, F. (2013). Villas romanas del Duero. Historia de un paisaje olvidado. Valladolid: CARGRAF.

Román Pulido, T. (1914). Apuntes para la historia de Mentesa Oretana. Don Lope de Sosa, 2, 117-120.

Romanelli, P. (1965). Riflessi di vita locale nei mosaici africani. En H. Stern y G. Ch. Picard (Eds.). Colloque. La Mosaïque Gréco-romaine, I (París, 1963) (pp. 275-284). París: Centre National de la Recherche Scientifique.

Romo Salas, A. S. (2003). Intervención Arqueológica en la Plaza de España, Écija. Memoria Final, vol. 1. Memoria I. (Informe inédito depositado en la Delegación de la Consejería de Cultura de la Junta de Andalucía). Sevilla.

Royo Guillén, J. I. (2001). El conjunto arqueológico de La Malena (Azuara, Zaragoza). En M. V. Escribano Paño y G. Fatás Cabeza (Eds.). La Antigüedad Tardía en Aragón (284714) (pp. 46-57). Zaragoza: Caja de Ahorros de la Inmaculada.

Salinas de Frías, M. (1990). Tradición y novedad en las leyes contra la Magia y los paganos de los emperadores cristianos. Antigüedad y Cristianismo, VII, 237-245.

San Nicolás Pedraz, P. (1994). Mosaicos y espacio en la villa romana de Fuente Álamo (Córdoba, España). En A. Mastino y P. Ruggeri (Eds.). Atti del X Convegno di Studi su l'Africa Romana (Oristano, 1992) (pp. 1289-1304). Sassari: Editrice Archivio Fotografico Sardo.

San Nicolás Pedraz, P. (1998). Arquitectura rural en los Mosaicos Hispanos. En M. Khanoussi, P. Ruggeri y C. Vismara (Eds.). Atti del XII Convegno di Studi su l'Africa Romana (Olbia, 1996) (pp. 891-906). Sassari: Editrice democrática Sarda.

Slim, H. (1995). Dionysos. En G. Mermet y M. BlanchardLemée (Auts.). Sols de l'Afrique Romaine. Mosaïques de Tunisie (pp. 87-119). París: Imprimérie nationale Éditions.

Smith, D. J. (1975). Roman mosaics in Britain before the Fourth Century. En H. Stern y M. Le Glay (Eds.). Actes $d u$ Colloque. La Mosaïque Gréco-romaine, II (Vienne, 1971) (pp. 266-288). París: Centre National de la Recherche Scientifique.
Squarciapino, M. F. (1987). Riflessi di vita locale nei mosaici africani. En A. Mastino (Ed.). Atti del IV Convegno di Studi su l'Africa Romana (Sassari, 1986) (pp. 193-200). Sassari: Università degli Studi di Sassari.

Sotomayor Muro, M. (1982). Penetración de la Iglesia en los medios rurales de la España tardorromana y visigoda. En Atti della XXVIII Settimana di studio del Centro Italiano di Studi sull'Alto Medioevo. Cristianizzazione ed organizzazione ecclesiastica delle campagne nell'alto medioevo; espansione e resistenze (Spoleto, 1980) (pp. 639-670). Spoleto: Presso la sede del Centro.

Torijano, P. (2000). El estudio de la magia en la Antigüedad tardía: Algunas consideraciones prácticas. Gerión, 18, 535-547.

Torres Carro, M. (2005). Nuevos mosaicos romanos del Noroeste de la Península Ibérica. En H. Morlier (Dir.). Colloque. La Mosaïque Gréco-romaine, IX, 1 (Roma, 2001) (pp. 477488). Collection de l'École française de Rome, 352. Roma: École française de Rome.

Toynbee, J.M.C. (1964). Art in Britain under the Romans. Londres: Oxford University Press.

Turcan, R. (1966). Les sarcophages romains à représentations dionysiaques. Essai de chronologie et d'histoire religieuse. París: E. de Boccard.

Vargas Vázquez, S. J. (2014). Diseños geométricos en los mosaicos de Écija (Sevilla). Oxford: British Archaeological Reports. John \& Erica Hedges Ltd.

Vargas Vázquez, S. J. (2016a). Diseños geométricos en los mosaicos del Conventus Astigitanus. Oxford: Archaeopress.

Vargas Vázquez, S. J. (2016b). Pavimentos musivos del yacimiento romano de Fuente Álamo (Puente Genil, Córdoba): los mosaicos de la villa. Romula, 15, 185-226.

Vargas Vázquez, S. J. y López Monteagudo, G. (2014). Talleres musivos hispanorromanos. Formas de producción y áreas de dispersión. En M. Bustamante Álvarez y D. Bernal Casasola (Eds.). Artífices idóneos. Artesanos, talleres y manufacturas en Hispania. Anejos de Archivo Español de Arqueología, LXXI (pp. 127-142). Mérida: Consejo Superior de Investigaciones Científicas.

Vargas Vázquez, S. J., López Monteagudo, G. y García-Dils de la Vega, S. (2017). Mosaicos romanos de Écija (Sevilla). Madrid-Écija: Consejo Superior de Investigaciones Científicas-Real Academia de Ciencias, Bellas Artes y Buenas Letras «Luis Vélez de Guevara» de Écija.

VV.AA. (2002). La Hispania del siglo IV. Administración, economía, sociedad, cristianización. En R. Teja (Ed.). Bari: Edipuglia.

Wattenberg, F. (1962). El mosaico de Diana en la Villa de Prado. Boletín del Seminario de Estudios de Arte y Arqueología de la Universidad de Valladolid, 28, 34-48. 